\title{
Acoustic masking in marine ecosystems: intuitions, analysis, and implication
}

\author{
Christopher W. Clark ${ }^{1, *}$, William T. Ellison ${ }^{2}$, Brandon L. Southall $^{3,4}$, Leila Hatch ${ }^{5}$, \\ Sofie M. Van Parijs ${ }^{6}$, Adam Frankel ${ }^{2}$, Dimitri Ponirakis ${ }^{1}$
}

\author{
${ }^{1}$ Bioacoustics Research Program, Cornell Laboratory of Ornithology, 159 Sapsucker Woods Road, Ithaca, New York 14850, USA \\ ${ }^{2}$ Marine Acoustics, 809 Aquidneck Avenue, Middletown, Rhode Island 02842, USA \\ ${ }^{3}$ Southall Environmental Associates, 911 Center Street, Suite B, Santa Cruz, California 95060, USA \\ ${ }^{4}$ Long Marine Laboratory, University of California, Santa Cruz, 100 Shaffer Road, Santa Cruz, California 95060, USA \\ ${ }^{5}$ Gerry E. Studds Stellwagen Bank National Marine Sanctuary, NOAA, 175 Edward Foster Road, Scituate, \\ Massachusetts 02066, USA \\ ${ }^{6}$ NOAA Fisheries, Northeast Fisheries Science Center, 166 Water Street, Woods Hole, Massachusetts 02543, USA
}

\begin{abstract}
Acoustic masking from anthropogenic noise is increasingly being considered as a threat to marine mammals, particularly low-frequency specialists such as baleen whales. Low-frequency ocean noise has increased in recent decades, often in habitats with seasonally resident populations of marine mammals, raising concerns that noise chronically influences life histories of individuals and populations. In contrast to physical harm from intense anthropogenic sources, which can have acute impacts on individuals, masking from chronic noise sources has been difficult to quantify at individual or population levels, and resulting effects have been even more difficult to assess. This paper presents an analytical paradigm to quantify changes in an animal's acoustic communication space as a result of spatial, spectral, and temporal changes in background noise, providing a functional definition of communication masking for free-ranging animals and a metric to quantify the potential for communication masking. We use the sonar equation, a combination of modeling and analytical techniques, and measurements from empirical data to calculate time-varying spatial maps of potential communication space for singing fin (Balaenoptera physalus), singing humpback (Megoptera novaeangliae), and calling right (Eubalaena glacialis) whales. These illustrate how the measured loss of communication space as a result of differing levels of noise is converted into a time-varying measure of communication masking. The proposed paradigm and mechanisms for measuring levels of communication masking can be applied to different species, contexts, acoustic habitats and ocean noise scenes to estimate the potential impacts of masking at the individual and population levels.
\end{abstract}

KEY WORDS: Communication masking $\cdot$ Ambient noise $\cdot$ Acoustic habitat $\cdot$ Communication space Spatio-temporal variability $\cdot$ Spectral variability $\cdot$ Cumulative effects $\cdot$ Marine mammals $\cdot$ Baleen whales

\section{INTRODUCTION}

The concept of acoustic interference is familiar to anyone who has tried to have a conversation in a noisy restaurant or to listen for the ring of a phone in another room through the acoustic clutter from a nearby television. In such situations the collective noise from many sources or the clutter of voices coming from a single location may impede one's ability to understand, rec- ognize or even detect sounds of interest. This type of acoustic interference is referred to as masking and results in the reduction of a receiver's performance, as the sound of interest cannot be effectively perceived, recognized or decoded. In the case of 2-way communication involving a sender and a receiver, masking results in the reduction of both the sender's and the receiver's performance; a phenomenon we will refer to here as communication masking. 
The term masking was borrowed by analogy from vision and in general refers to the failure by a person to recognize the occurrence of one type of stimulus as a result of the interfering presence of another stimulus. Auditory masking was first empirically measured and quantified by experiments testing a listener's ability to hear a test tone in the presence of noise (Tanner 1958). In humans, masking is the amount (or process) by which the audibility threshold for one sound is raised by the presence of another sound (Moore 1982, p 74).

Early masking studies in humans showed that tonal signals are most effectively masked by tonal sounds or broadband noise with frequencies similar to the signal's frequency (Wegel \& Lane 1924, Fletcher 1940). Further studies revealed that this basic principle of masking applies to non-human mammals as well (Scharf 1970, Fay 1988). These observations along with additional evidence suggest that the mammalian auditory system segregates an incoming acoustic signal into its constituent frequencies, leading to optimization of signal-to-noise ratio and parallel processing of the harmonic components of complex sounds (Moore 1982, Fay 1992, Niemiec et al. 1992).

There are 2 major, but not necessarily exclusive, categories of masking: energetic masking and informational masking (Ihlefeld \& Shinn-Cunningham 2008, Yost et al. 2008). Traditional energetic masking refers to the case when the masking sound contains energy in the same frequency band and occurs at the same time as the signal of interest, such that the signal is inaudible. In contrast, informational masking is considered to operate further along in the auditory process and occurs when the signal is still audible but cannot be disentangled from a sound with similar characteristics (Watson 1987, Brungart 2004). Most of us are familiar with both energetic and informational masking, and have experienced situations which involved mixtures of both forms.

There has been substantial research on the effects of noise on human hearing and speech communication (e.g. Pearsons et al. 1977, Nilsson et al. 1994; for reviews see Kryter 1994, Miller 1997, Yost 2000), concentration and cognitive functions (e.g. general 'annoyance'), and physiological functions, including stress responses (e.g. Schultz 1978, Beranek \& Ver 1992, Tafalla \& Evans 1997, Evans 2001). These impacts can occur in environments with persistent levels of elevated ambient noise, such as under industrial work conditions, where chronic exposure can result in hearing loss (Kryter 1994). Such physiological effects, although not considered communication masking in the traditional sense of the term, can result in the loss of one's ability to detect important sounds. Additionally, studies have been conducted on how people use sound as a means of sensing the acoustic 'scene' in a spatial manner analogous to visual field perception (Bregman 1990), as well as on the longer-term and larger-scale deleterious effects of the noise environment on human development and behavior (e.g. Evans 2001, 2003). For marine mammals, Richardson et al. (1995) presented an excellent overview and outline of noise masking, while recognizing the inherent difficulties of quantifying the potential effects. The analytical paradigms arising from these and other studies provide a useful starting framework by which to explore the effects of noise on marine animals (e.g. Southall et al. 2007).

Masking in a broad sense is a key concern regarding the non-injurious impact of interfering sound on marine wildlife, and the potential for communication masking is the aspect most often associated with long-term effects of anthropogenic sound. That noise from anthropogenic sources might affect marine mammal communication was first articulated by Payne \& Webb (1971), who proposed that the collective, very low frequency noise $(<100 \mathrm{~Hz})$ from ocean shipping might reduce the range over which blue (Balaenoptera musculus) and fin (B. physalus) whales are able to communicate. These whales are members of a remarkable group of marine mammals that have adapted to an aquatic existence over tens of millions of years (see Reynolds \& Rommel 1999). During this evolutionary period, marine mammals evolved many ingenious mechanisms for producing, receiving and using sound for a variety of biological functions (e.g. Schusterman 1981, Clark 1990, Au 1993, Richardson et al. 1995, Tyack 1998, Wartzok \& Ketten 1999, Clark \& Ellison 2004).

Different groups of marine mammals appear to be tuned to different frequency bands, despite being generally quite similar in how they hear in the presence of interfering noise, and having ears that appear to be fundamentally similar in structure and function. Recently, Southall et al. (2007) suggested using an 'M-weighting' function ${ }^{1}$ as an appropriate method to account for a marine mammal's auditory sensitivity in assessing potential impacts of exposure to high-level sounds. For baleen whales, Richardson et al. (1995) and Clark \& Ellison (2004) deduced that low-frequency auditory thresholds are very likely ambient noise limited. Consequently, these low-frequency specialists will be disproportionately affected by changes in low-frequency noise levels and thus particularly susceptible to the masking effects of noise on their communication signals. It is likely that acoustic masking by anthropogenic sounds is having an increasingly prevalent impact on animals' access to acoustic information that is essential

\footnotetext{
1Derived for different marine mammal 'functional hearing groups' and in a manner based on the $\mathrm{C}$-weighting function used in humans.
} 
for communication and other important activities such as navigation and prey/predator detection. In an evolutionary time frame relevant to species adaptations, these impacts are essentially immediate. Developing a critical and extensive understanding of these issues will require a broad-based, rigorous and quantitative approach that better identifies the underlying relationships, factors, and variables.

There has been an increasing level of discussion and debate over how marine mammals may be affected by anthropogenic noise in the ocean (see NRC 2000, 2003, 2005, Cox et al. 2006, Southall et al. 2007), with most attention directed at understanding the physiological and behavioral impacts from short-term, small-scale, high intensity exposures (i.e. acute). There is recognition that long-term, large-scale (i.e. chronic), low intensity noise exposures might also be affecting individuals and populations, and communication masking is often mentioned or implied as a probable mechanism (Payne \& Webb 1971, Richardson et al. 1995, NRC 2000, 2003, Southall 2005, Nowacek et al. 2007, Hatch et al. 2008). Richardson et al. (1995) outlined the basic components for, and a few models have been created to estimate, the spatial extent of communication masking. One such model for beluga whales Delphinapterus leucas considered the physical environment as well as both the acoustic behavior and hearing ability of the animal (Erbe \& Farmer 2000). Nevertheless, there has not yet been an overarching paradigm for evaluating or measuring, in a realistic spatial sense, the potential impacts (either short- or long-term) from communication masking on free-ranging animals.

Here we consider acoustic communication masking in the marine environment with particular attention to a major group of marine mammals, the mysticetes, due to their low-frequency vocalization range and the ubiquitous growth in oceanic noise in this same range (Andrew et al. 2002, McDonald et al. 2006). We enumerate a number of key concepts such as acoustic habitat, acoustic scene, acoustic space and acoustic ecology to expand on some previous syntheses and recent research (e.g. Richardson et al. 1995, Clark \& Ellison 2004, Southall et al. 2007, Hatch et al. 2008). We introduce the concept of a dynamic spatio-spectraltemporal acoustic habitat, and use this perspective to develop analytical representations by which to study the masking effects of noise on acoustic communication. We formalize a protocol that integrates a form of the sonar equation (Urick 1983) with biological knowledge to quantify the effects of an actual moving anthropogenic noise source on the area over which a single animal's acoustic communication signal might be recognized by a uniformly distributed set of conspecifics. The result is standardized by referencing that area to the ambient noise conditions without anthropogenic sources to yield a time-varying masking index. This procedure for a single, stationary calling animal in a time-varying acoustic scene is then expanded to a population of stationary calling animals to quantify variability of communication masking throughout a habitat region. Furthermore, we generalize the algorithm to include multiple noise sources and thereby formalize a method for quantifying the cumulative effects of co-varying numbers and types of anthropogenic sources.

\section{Background}

A broad consideration of acoustic masking must include the masking of conspecific communications, as well as the masking of other biologically important sounds (e.g. echolocation sounds for foraging and sounds from predators) and abiotic sound cues (e.g. sounds from a distant shoreline, earthquakes, volume reverberation). Furthermore, we must consider both short-term, proximate effects (e.g. the temporary inability of an animal to hear the communication calls of a conspecific) as well as long-term, ultimate effects (e.g. decreased survivorship and fecundity as a result of the persistent degradation of an acoustic habitat over an animal's lifetime).

A central concept is the effective 3-dimensional space over which bioacoustic activity occurs ('bioacoustic space'). Some of the most common types (Table 1) include the space over which (1) sounds from

Table 1. Matrix listing different types of acoustic spaces that can be affected by noise masking. NA: not applicable

\begin{tabular}{|c|c|c|c|c|}
\hline \multirow[t]{2}{*}{ Receiver } & \multicolumn{4}{|c|}{ Sound source } \\
\hline & Self & Conspecific & Other species & Abiotic \\
\hline Self & $\begin{array}{l}\text { Echolocation: navigation } \\
\text { and food finding }\end{array}$ & Communication & $\begin{array}{l}\text { Predator avoidance, } \\
\text { food finding }\end{array}$ & $\begin{array}{l}\text { Navigation, } \\
\text { food finding }\end{array}$ \\
\hline Conspecific & Communication & $\begin{array}{l}\text { Eavesdropping, bi-static navi- } \\
\text { gation, bi-static food finding }\end{array}$ & NA & $\begin{array}{l}\text { Bi-static } \\
\text { navigation }\end{array}$ \\
\hline Other species & Detection by predator & Bi-static food finding & Eavesdropping & NA \\
\hline
\end{tabular}


an individual animal can be heard by other conspecifics, or a listening animal can hear sounds from other conspecifics (i.e. 'communication space' or 'bistatic space'); (2) an individual animal can hear bioacoustic signals from itself (i.e.' echolocation' or 'echoranging space'); (3) an individual animal can hear sounds from interacting conspecifics (i.e. 'eavesdropping space'); (4) an individual animal can hear biologically relevant signals from animals other than conspecifics (i.e. 'predator space'); (5) an individual animal can hear biologically relevant food resource cues (i.e. 'volume reverberation space'); and (6) an individual animal can hear physically relevant sound cues from oceanographic features (i.e. 'reverberation space', 'internal wave space') $)^{\underline{2}}$. At any one time an individual animal has multiple acoustic spaces, some dominated by factors operating within the biological, evolutionary domain (e.g. receiver characteristics including hearing abilities as well as source level, directivity, and frequency band of a calling conspecific) and some dominated by physical factors operating outside of an evolutionary domain (e.g. water depth, sound velocity profile, substrate composition, backscatter), and some of which are co-dependent and co-varying.

We define 'communication space' as the volume of space surrounding an individual, within which acoustic communication with other conspecifics can be expected to occur. It is similar to 'active space' (e.g. Brenowitz 1982, Janik 2000), but here we expand on this concept with regard to acoustic communication. The size and shape of any particular bioacoustic space is influenced by multiple factors which vary differently over time. For example, the communication space of a caller will vary considerably depending on a host of variables relating to both sender and receiver, including source level, directivity, and orientation; sound transmission path conditions; ambient noise; and receiver orientation and detection capabilities. The values of these factors and their combinations will vary for different bioacoustic spaces and different species. For example, an animal's echolocation space is likely to be smaller than its communication space because the transmission loss for the echoing signal at a given distance is twice that for a communication signal; this would be even more so if the echolocation signal is much higher in frequency than the communication signal, and thus subject to additional scattering and absorption losses. Likewise, the communication space

${ }^{2}$ There are cases where information is available to an animal via the acoustic channel from the combination of a bioacoustic signal and the effects of sound propagation on that signal, for example the multi-modal arrivals of a communication call (Premus \& Spiesberger 1997). We recognize but do not consider these other cases here.
Table 2. List of abbreviations

\begin{tabular}{|c|c|c|c|}
\hline$C R$ & \multicolumn{2}{|l|}{ Communication range } & \\
\hline$C S$ & \multicolumn{2}{|l|}{ Communication space $\left(\mathrm{km}^{2}\right)$} & \\
\hline$D I$ & \multicolumn{2}{|l|}{ Directivity index (dB) } & \\
\hline$D T$ & \multicolumn{2}{|l|}{ Detection threshold (dB) } & \\
\hline$f_{0}$ & \multicolumn{2}{|l|}{ Mean or center frequency (Hz) } & \\
\hline$L_{e q}$ & \multicolumn{2}{|l|}{ Equivalent level (dB) } & \\
\hline$M$ & \multicolumn{2}{|l|}{ Communication masking index } & \\
\hline$N L$ & \multicolumn{2}{|l|}{$\begin{array}{l}\text { Noise band level ( } \mathrm{dB} \text { re } 1 \mu \mathrm{Pa} \text { ) at a receiver, i.e. } \\
\text { the sum of ambient noise and noises from } \\
\text { specific sources with distinctive spatial and } \\
\text { temporal parameters }\end{array}$} & \\
\hline NSL & \multicolumn{2}{|l|}{ Noise source level (dB) } & \\
\hline NTL & \multicolumn{2}{|l|}{ Noise transmission loss $(\mathrm{dB})$} & \\
\hline PCS & \multicolumn{2}{|l|}{ Potential communication space $\left(\mathrm{km}^{2}\right)$} & \\
\hline$P R$ & \multicolumn{2}{|l|}{ Probability of recognition } & \\
\hline$P S D$ & \multicolumn{2}{|l|}{ Power spectral density } & \\
\hline$R_{0}$ & \multicolumn{2}{|l|}{ Range between source and receiver (m) } & \\
\hline$R D$ & \multicolumn{2}{|l|}{ Recognition differential (dB) } & \\
\hline$R_{I N T}$ & \multicolumn{2}{|l|}{ Range interval (m) } & \\
\hline$R L$ & \multicolumn{2}{|l|}{ Received level of sound at a receiver (dB) } & \\
\hline rms & \multicolumn{2}{|l|}{ Root mean square } & \\
\hline $\mathrm{S}$ & \multicolumn{2}{|l|}{ Sender } & \\
\hline SBNMS & \multicolumn{2}{|l|}{ Stellwagen Bank National Marine Sanctuary } & \\
\hline$S E$ & \multicolumn{2}{|l|}{ Signal excess $(\mathrm{dB})$} & \\
\hline$S E L$ & \multicolumn{2}{|l|}{ Sound energy level ( $\mathrm{dB}$ re $\left.1 \mu \mathrm{Pa}^{2} \mathrm{~s}\right)$} & \\
\hline$S G$ & \multicolumn{2}{|l|}{ Signal processing gain $(\mathrm{dB})$} & \\
\hline$S L$ & \multicolumn{2}{|l|}{$\begin{array}{l}\text { Source level of sound as emitted with reference } \\
\text { to a } 1 \mathrm{~m} \text { distance, dB re } 1 \mu \mathrm{Pa} @ 1 \mathrm{~m}\end{array}$} & \\
\hline$S N R$ & \multicolumn{2}{|l|}{$\begin{array}{l}\text { Signal-to-noise ratio (since this is a ratio there is } \\
\text { no reference unit) }\end{array}$} & \\
\hline$S P L$ & \multicolumn{2}{|l|}{ Sound pressure level $(\mathrm{dB})$} & \\
\hline$S R D$ & \multicolumn{2}{|l|}{$\begin{array}{l}\text { Source-receiver depth }(\mathrm{m}) \text {, depth of calling and } \\
\text { receiving whales }\end{array}$} & \\
\hline$T$ & \multicolumn{2}{|l|}{ Duration (s) } & \\
\hline$T L$ & \multicolumn{3}{|l|}{$\begin{array}{l}\text { One way transmission loss between sound } \\
\text { source and receiver inclusive of spreading losses, } \\
\text { refraction, scattering, absorption and other }\end{array}$} \\
\hline & \multirow{2}{*}{$\begin{array}{l}\text { boundary losses (dB). We use the KRAKEN } \\
\text { model to calculate TL (Porter \& Reiss 1985) }\end{array}$} & & Note: \\
\hline & & The & units for SNR \\
\hline$W$ & Bandwidth (Hz) & & \\
\hline$\rho c$ & Acoustic impedance & & $\begin{array}{l}\text { orrected after } \\
\text { publication }\end{array}$ \\
\hline
\end{tabular}

of a pilot whale whistling in the $7-15 \mathrm{kHz}$ frequency band will be much smaller than the communication space of a fin whale calling in the $30-80 \mathrm{~Hz}$ band, even if the output levels are similar, as a result of physical acoustics. While communication space has not been extensively studied in animals, some interesting calculations and estimates have been made for red-winged blackbirds Agelaius phoeniceus (Brenowitz 1982), bowhead whales Balaena mysticetus (Richardson et al. 1995), blue monkeys Cercopithecus mitis and greycheeked mangabees Cercocubus albigena (Brown 1989), yellowfin tuna Thunnus albacares (Finneran et al. 2000), bottlenose dolphins (Tursiops truncatus (Janik 2000), and northern elephant seals Mirounga angustirostris (Southall et al. 2003). 
In the following section we translate the concept of acoustic space as outlined above into a series of mathematical expressions based on a family of sonar equations. We use this modeled approach as the framework by which to quantify the masking effects of ambient noise and specific sound sources on communication space. We provide examples of communication masking due to shipping noise for 3 mysticete whale species. A solution for cumulative impact from multiple noise sources is achieved by generalizing the algorithm, and the resultant metric is standardized by reference to the amount of communication space that would have been available under what we define as ancient ambient noise conditions.

\section{METHODOLOGY}

A model of communication masking must include the basic elements of source characteristics, acoustic propagation and received sound exposure, with the result cast in metrics that provide a methodology for assessing the relative effects of communication masking on the animal's bioacoustic space. The key elements in the model must at least extend from the noise(s) and/or sound(s) experienced by the animal through the initial stages of the animal's auditory processes when the sound of interest is recognized. Table 2 lists terms and abbreviations used.

\section{Examples}

Fig. 1 shows $24 \mathrm{~h}$ spectrograms based on acoustic data collected with similar recorders in 2 different habitats with known populations of fin whales; Fig. 1A is from the Gulf of California, a habitat with low background noise conditions, while Fig. 1B is from the Mediterranean Sea, a habitat with high background noise conditions (Clark et al. 2002, Croll et al. 2002). Fin whales were singing in both habitats and are very evident in the Baja California habitat (Fig. 1A), but barely evident in the Mediterranean habitat which is dominated by shipping noise (Fig. 1B).

In Fig. 2, we convert those data into quantile statistics for the power spectral density $(P S D)$ distribution. For the Gulf of California habitat (Fig. 2A), this reveals a dominant $20 \mathrm{~Hz}$ peak representing the collective voices of fin whale singers, while for the Mediterranean habitat (Fig. 2B) there is no apparent $20 \mathrm{~Hz}$ peak, and the contribution of singers to the spectral energy distribution is hidden within a broader, 15-80 Hz band of noise. Thus fin whale singers in the Gulf of California are not masked by noise in their communication band (18-28 Hz), while band level noise in the Mediterranean Sea, at least for this $24 \mathrm{~h}$ period, is so high that singers might have a problem being heard by other fin whales. Conversion of these kinds of acoustic scenes into measures of communication masking requires careful consideration and inclusion of variability in the temporal, spectral and spatial dimensions of the acoustic environment at biologically meaningful resolutions. That is, the temporal resolution of the analysis should match the durations of the sounds produced and perceived by the species of concern, just as the spectral resolution should be matched to the frequency bands in which the species communicates, and the spatial resolution should be matched to an area over which the animal communicates.

An example of adjusting spectral resolutions to match the frequency characteristics of species-specific whale sounds may be seen in recent data collected
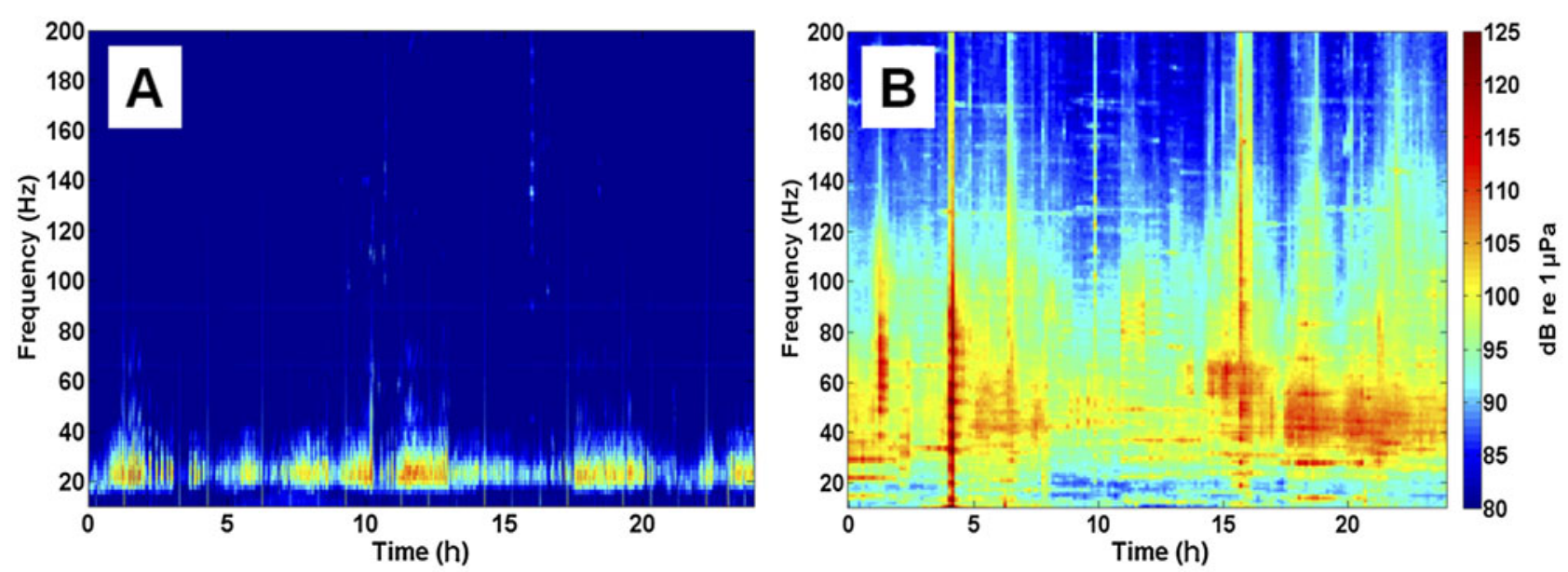

Fig. 1. Examples of $24 \mathrm{~h}$ acoustic scenes for 2 habitats in which male fin whales were singing: (A) Gulf of California and (B) Mediterranean Sea (2 kHz sampling rate, 1024 pt FFT, $50 \%$ overlap, Hanning window). Both recorders were similar with flat $( \pm 1.0 \mathrm{~dB})$ frequency response between 10 and $585 \mathrm{~Hz}$. Scale bar indicates rms pressure level in dB re $1 \mu \mathrm{Pa}$ 

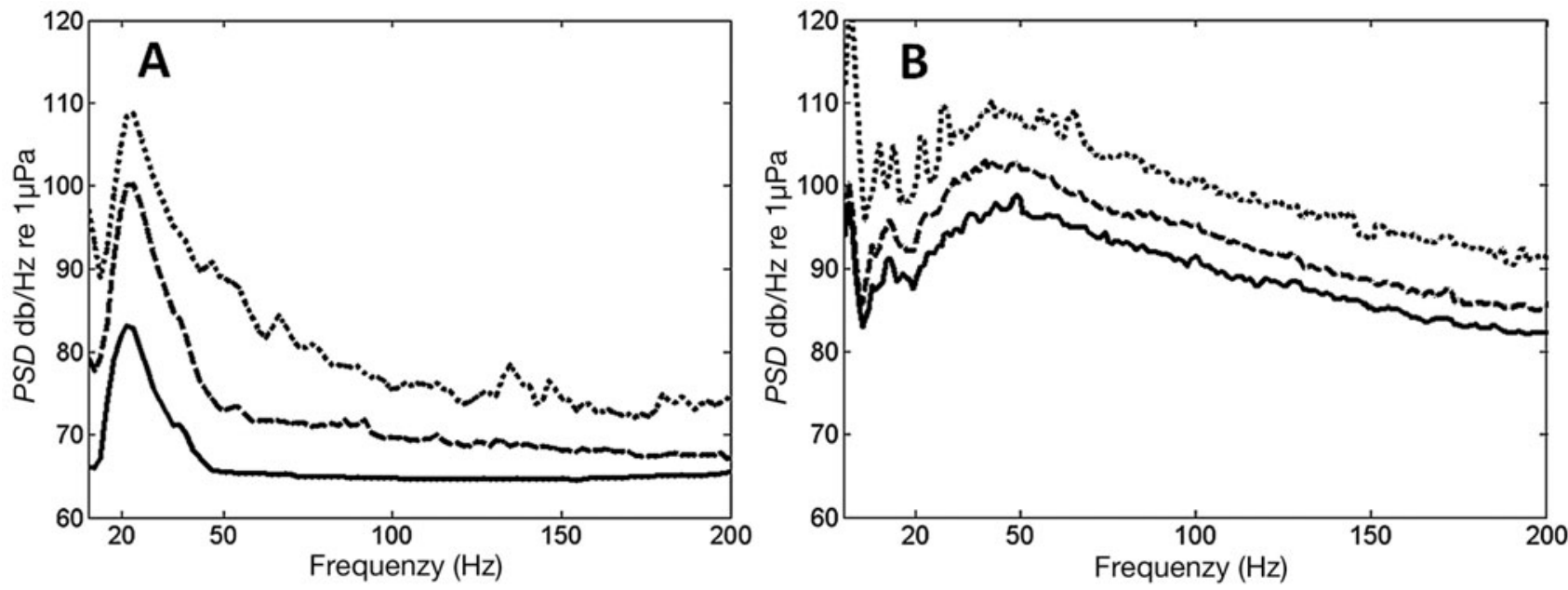

Fig. 2. Order statistic analysis for the $24 \mathrm{~h}$ acoustic samples in which fin whales were singing as shown in Fig. 1 for (A) Gulf of California and (B) Mediterranean Sea; order statistics: 50th percentile (middle line), 95th percentile (top line) and 5th percentile (bottom line). $P S D$ : power spectral density
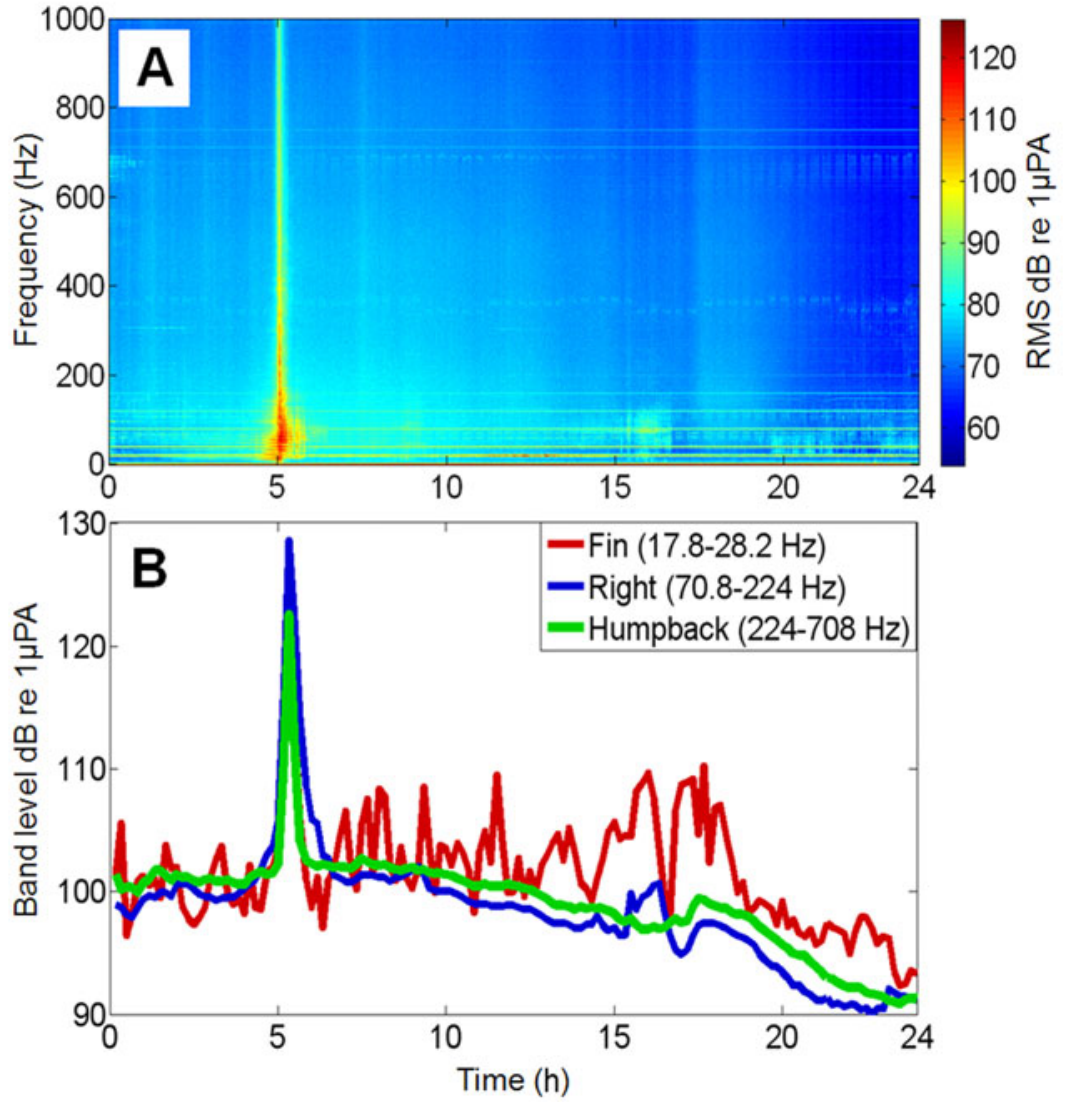

Fig. 3. Example of $24 \mathrm{~h}$ (A) low-frequency acoustic scene and (B) noise levels in the species-specific communication frequency bands for fin, humpback and right whales. Data are from an autonomous seafloor recorder in the Stellwagen Bank National Marine Sanctuary on 27 December 2007. Noise levels are $L_{e q}$ for the fin, humpback and right whale 1/3rd-octave bands. The noise spike around 05:05 $\mathrm{h}$ is from the passage of a commercial ship, the MV 'New England', at a distance of ca $0.5 \mathrm{~km}$, while the less obvious increase in noise levels between 15:00 and 18:00 $\mathrm{h}$ is from the passage of a second ship, the MV 'Marchekan', at a distance of $13 \mathrm{~km}$ from an autonomous seafloor recorder in the Stellwagen Bank National Marine Sanctuary (SBNMS), an area with known seasonal populations of fin, humpback and North Atlantic right whales (Fig. 3). On 27 December 2007, a commercial vessel, the MV 'New England', transited through the northern part of the sanctuary from 04:40 to 06:30 h, passing within ca. $0.5 \mathrm{~km}$ of the recorder at 05:05 h. A second commercial vessel, the MV 'Marchekan', passed through the middle part of the sanctuary from 14:50 to 20:50 h, passing within $13 \mathrm{~km}$ of the recorder at 16:30 h. The close passage of the MV 'New England' is seen as a dramatic broadband spike in the spectrogram (Fig. 3A), while Fig. 3B tracks the recorded sound levels in 3 frequency bands matching those of singing fin, singing humpback and calling right whales. This quantification of noise level for each of the 3 species demonstrates how the same sound source will have different relative levels and variability depending on the frequency band of interest.

To gain a sense of how sound is distributed throughout the acoustic environment in which whales occur, one needs to spatially sample a large area that encompasses a representative portion of their acoustic habitat, thus adding the critical dimension of spatial variability to the communication masking process.

Such spatial distribution of acoustic power from a single source can be seen in 
the 3 different species-specific frequency bands for a 1 min sample collected by a 19-element array of recorders off Massachusetts (Fig. 4). The relatively high noise levels at the center recorder (approx. $42.4^{\circ} \mathrm{N} / 70.6^{\circ} \mathrm{W}$ ) in Fig. $4 \mathrm{~B}, \mathrm{C}$ are a result of construction noise, while the high level to the right of center in

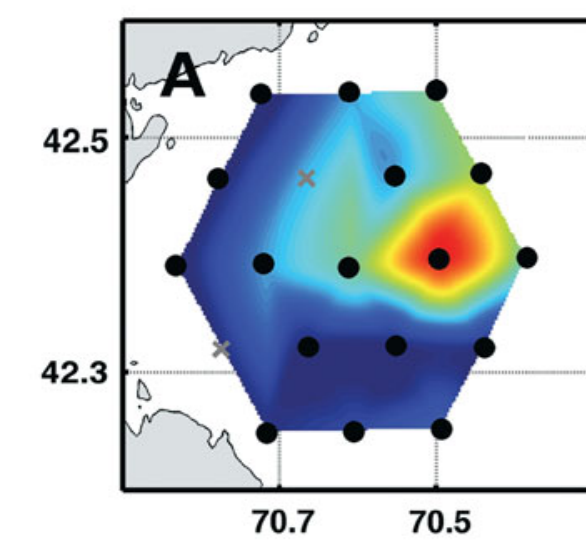

\section{$\mathrm{dB}$ re $1 \mu \mathrm{Pa}$}
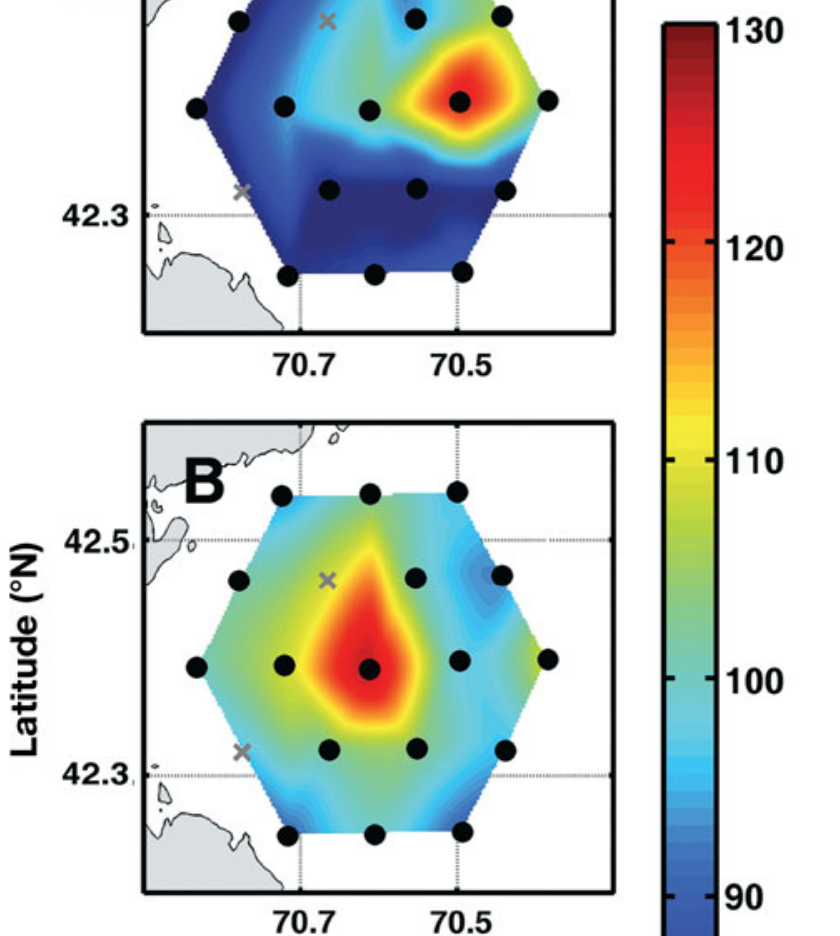

$-110$

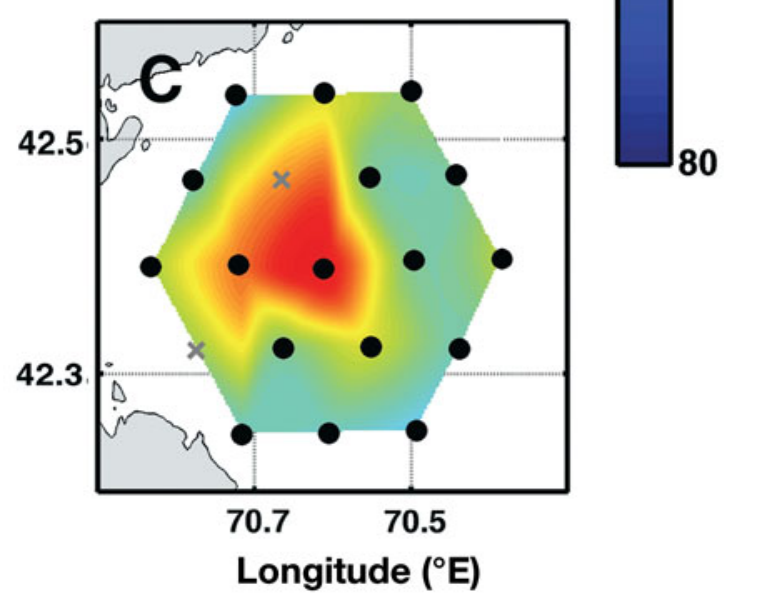

Fig. 4. Examples of ambient noise fields for 3 different frequency bands in a 1 min sample from an array of 19 popups (๑) deployed in Massachusetts Bay and centered on a construction site: acoustic noise field in the (A) $18-28 \mathrm{~Hz}$ fin whale band; (B) 224-708 Hz humpback whale band; (C) 71-224 Hz right whale band
Fig. 4A is from a singing fin whale. There were no singing humpback whales or calling right whales in the area during this 1 min sample.

This illustrates an important feature of the sound environment surrounding a potential receiver; noise fields around receivers are not symmetrical. Furthermore, the spatial directivity of each sound source contributing to an auditory scene varies; some sources are fairly omnidirectional (e.g. very low-frequency whale calls or the broadband, low-frequency noise from distant shipping traffic), some are more directional (e.g. high pitched pilot whale whistles or the noise from a small boat passing overhead). The ability of a listener to spatially segregate signals from noise in a complex auditory scene is referred to as the 'cocktail party effect,' and there is a fairly extensive body of research on this subject for humans (Cherry \& Taylor 1954, Broadbent 1958, Durlach \& Colburn 1978, Handel 1989, Bregman 1990, Arons 1992). Here we assume that when the sound source components contributing to the acoustic scene at a receiving animal have directional-spatial cues, the receiver can separate out these different sources as coming from different directions. This ability to spatially segregate a signal arriving from a conspecific sender from the non-signal sounds contributing to the noise field (i.e. cocktail party effect or spatial release) provides a receiving animal with an improved communication space, while the spatial directivity of noise sources imparts a noise-specific asymmetry to the noise field surrounding the receiver which, in turn, imparts asymmetry to the sender's communication space. In this paper we assume that marine mammals have the ability to spatially segregate signals and noise (e.g. Turnbull 1994, Holt \& Schusterman 2007). We therefore include a representative term for signal directionality in our model of communication masking for free-ranging animals, but we do not give it an empirically informed value. Exclusion of this explicit allowance for directional hearing means that our estimates of masking effects will be overestimated in this first-order evaluation.

As described above, acoustic interference includes both communication masking and clutter ${ }^{\underline{3}}$, where acoustic interference results in a reduction or elimination of an animal's ability to recognize communication sounds. Although we understand that the distinction between communication masking and clutter is not absolute, for purposes of simplicity, we refer here to communication masking as the loss of communication

\footnotetext{
${ }^{3}$ Acoustic clutter includes the entities in the aggregate of received sound that have acoustic features that can be confused with a biological signal of interest. By this terminology broadband noise from a discrete source, such as a ship, is noise, not clutter.
} 
space as a result of noise and/or sounds in the ambient environment.

We now address the following types of questions: What is the impact of the high levels of noise in the frequency band of fin whale communication in the Mediterranean Sea? How close do right whales have to be to hear each other when a ship passes close by? What is the area over which a singing humpback whale might be heard by other whales? How much does a whale's communication space vary when a noise source, natural or anthropogenic, affects its acoustic habitat? What is the impact of a loss of communication space on individual or population-level success, and can we quantify these answers to take into account the spatial, spectral and temporal dimensions of variability as they apply to different species in different communication contexts?

\section{Principles of communication masking}

Here we apply biological considerations to further tune the selection of parameters representing the degree to which signal and noise overlap in frequency, time and space. This results in calculations of signalto-noise ratios $(S N R)$ that are adjusted to speciesspecific parameters and thereby provide us with a biologically informed metric for evaluating the ability of an animal to detect and recognize communication signals under different noise conditions. In other words, the result is a metric for estimating the amount by which noise reduces the ability of a receiving animal to recognize the sounds of a conspecific.

The terms for these 3 factors relative to acoustic communication are:

(1) Frequency band: a frequency range within which background noise could mask a biologically meaningful sound. Here the value of this frequency band is based on the set of 1/3rd-octave bands that span the species-specific communication sounds produced by the species of interest. For species whose communication sounds span a wide frequency range (e.g. humpback and bowhead whales) this frequency band is most likely wider than a critical bandwidth (Fay 1988).

(2) Integration-time: the duration over which ambient noise could mask the recognition of a biologically meaningful sound. The value of this factor is based on the assumed functional duration of the types of communication sounds produced by the species of interest. In the simple cases addressed here we assume that the noise occurs simultaneously with and throughout the entire duration of the sound, while recognizing that communication masking can occur when the noise and sound of interest only partially overlap in time or when the noise precedes the sound.
(3) Space: the Euclidean space over which ambient noise could mask a communication sound. The value of this acoustic-space factor is based on the assumed functional communication range for the type of sound produced by the species of interest.

For our considerations, spectral overlap is accounted for by calculating received levels $(R L)$ and $S N R$ levels in the $1 / 3$ rd-octave bands encompassing the communication signal of interest (e.g. a contact call or song) ${ }^{\mathbf{4}}$, temporal overlap is accounted for by calculating $R L \mathrm{~s}$ and $S N R$ levels in those bands of interest for time windows matching the durations of the communication signal of interest (e.g. $2 \mathrm{~s}$ for a right whale contact call or $10 \mathrm{~s}$ for a humpback song phrase), and spatial overlap is accounted for by limiting the communication masking area to an assumed transmission distance for the signal of interest (e.g. $20 \mathrm{~km}$ ).

Calculating communication masking is primarily a matter of $S N R$; where $S N R$ at a receiver $(R)$ for a signal from a sender $(S)$ is calculated for the species-specific frequency band and measured $\mathrm{as}^{\underline{\mathbf{5}}}$ :

$S N R_{R}=R L_{R}-N L_{R}$, in $\mathrm{dB}$

(this is a ratio, so no reference unit)

$R L_{R}=$

$10 \log [$ received signal intensity/reference intensity]

$N L_{R}=10 \log$ [noise intensity/reference intensity]

$R L_{R}=S L_{S}-T L_{S}$

and where the reference intensity is that of a plane wave of root-mean-squared (rms) pressure relative to $1 \mu \mathrm{Pa}$. For practical purposes of sound propagation in the ocean, intensity is well estimated by the rms value of $\left[P^{2}(\rho c)^{-1}\right]$, where $P$ is the pressure and $\rho c$ is the characteristic impedance of sea water. Thus, the sonar equation values can all be based on rms pressure measurements.

Therefore,

$$
N L=N L_{A}+\sum_{1}^{n} N L_{n}
$$

where $N L_{A}$ is the ambient noise level and $N L_{n}$ is the noise level for the $n$th noise source. Each discrete noise source experiences transmission loss:

$$
N L_{n}=N S L_{n}-N T L_{n}
$$

${ }^{4}$ Given the known asymmetry in noise communication masking (i.e. high levels of noise in a lower frequency band will inhibit the detection and recognition of sound in a higher band) one could extend this index to include higher 1/3rd-octave bands. In our treatment here, we do not include the effects of upward communication masking.

${ }^{5}$ All further uses of $S N R$ and related sonar equation terms will, by default, assume that $S N R$ is measured for a specified frequency band spanning individual sets of 1/3rd-octave bands, not a single frequency, and are thus rms band level measurements. 
where $N S L_{n}$ and $N T L_{n}$ are the noise source level and noise transmission loss for the discrete noise source $n$, respectively. Therefore, combining Eqs. (1), (2) \& (3), the total $S N R$ for a sender's signal at a receiver is:

$$
S N R_{R}=R L_{R}-N L_{A}-\sum_{1}^{n}\left(N S L_{n}-N T L_{n}\right)
$$

Due to the natural fluctuations of background noise and related features of sounds, signals are not normally perceived at a value of $S N R=0$, but at some value (receiver system specific) greater than zero. This difference is termed the detection threshold $(D T)$ and the relation between $D T$ and $S N R$ is undertaken by another term called signal excess ( $S E)$. Thus, a new member of the sonar equation family is:

$$
S E=S N R-D T
$$

The value at which $S E=0$ is also defined routinely with respect to sonar systems as the $50 \%$ probability of detection. Here we recognize that whales have attributes that may allow them to detect signals better than Eq. (4) would imply. Let us enhance the DT term with additional properties expected to be present in the whale auditory 'system', and rename this expanded term, recognition differential $(R D)$. For the first attribute in the $R D$ term, we will continue to follow the sonar analogy and call it the directivity index $(D I)$ and claim it to be analogous to binaural hearing gain. The second attribute in the $R D$ term is related to the duration and broadband nature of signals used by many underwater animals. We will call this second term signal processing gain $(S G)$ and give it a placeholder value of $10 \log (T W)$, where $T W$ refers to the time product of a vocalization's duration $(T)$ and bandwidth $(W)$. In the analogous sonar system using matched filter processing, this time-bandwidth gain is normally split such that $10 \log (T)$ is added to the source level (SPL) to

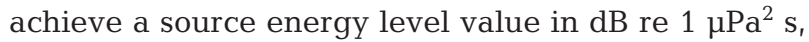
while $10 \log (W)$ is added to $-N L$ which changes the effective $N L$ measurement from a band level $S P L$ to a spectrum level measurement in $\mathrm{dB}$ re $1 \mu \mathrm{Pa}^{2} \mathrm{~Hz}^{-1}$. In our formulation, however, we will transform Eq. (4) into:

where

$$
S E=S N R-R D
$$

$$
R D=D T-(D I+S G)
$$

In essence the recognition differential accounts for an animal's expected ability to recognize, not just detect, low level signals in background noise. By formulating the equation in this manner, we implicitly recognize that in the case where $D I$ is unknown (or thought to be minimal), and $S G$ might not apply $\underline{6}, R D$ resolves back to the classic $D T$.

The 2-D spatial and spectral (frequency overlap) components of a simplified communication masking model are shown in Fig. 5ㅍ․ Fig. 5B,C identify the importance of frequency bandwidth and duration on the process of recognition and on the impact that communication masking could have on the communication process. In Fig. 5B, for the receiving whale, $W_{R}$, the $S N R$ of the call from the sending whale, $\mathrm{W}_{\mathrm{S}}$ is barely above the spectrum level of the ship and likely below the band level of the ship (not shown). A more realistic assessment of communication masking should include the recognition differential, $R D^{\underline{8}}$, by adding some form of signal processing gain $(S G)$ and directive hearing $(D I)$ to the whale's reception capability as given in Eqs. (5) \& (6). When these factors are included (Fig. 5C), if $S G$ (i.e. the $T W$ gain) and $D I$ combined are sufficient, the $S E$ for $\mathrm{W}_{\mathrm{S}}$ ' call is likely sufficient for it to be detected by $\mathrm{W}_{\mathrm{R}}$.

As alluded to above, one method to estimate $S G$ that is straightforward (and possibly not as good as animals actually accomplish) is a simple matched filter. The matched filter approach calculates $S N R$ not on the basis of power signal-to-noise, but on the basis of energy signal-to-noise. The theoretical gain, $S G$, of such a processor over a simple bandpass filter is nominally equal to $10 \log (T W)^{\mathbf{9}}$. Therefore, a vocalization of duration, $T$, and bandwidth, $W$, will theoretically provide a signal processing gain against relatively uniform noise of:

$$
S G=10 \log (T W)
$$

Signal bandwidth and time-bandwidth product are extremely important features. Bandwidth becomes an enormously valuable factor in a wide range of bioacoustic functions if some form of broadband processing can be implemented. One benefit of a broadband signal is that it offers the possibility for a receiver to successfully detect and recognize the signal in acoustic environments where portions of the signal are lost; for example, as a result of frequency dependent multi-

\footnotetext{
${ }^{6}$ In the recognition process, we assume that the attending receiver anticipates knowledge of a signal to achieve the signal processing gain. Hypothesizing that a vocalizing animal would only possess such a signal for conspecific or known predator sounds, we speculate that this gain likely does not apply to all types of sounds.

${ }^{7}$ Not shown in this figure is the 3-D spatial variability as a result, for example, of sound propagation throughout the water column or the depths of the calling and receiving whales. These factors can be dealt with in the model, but for purposes of simplicity are not included here.

${ }^{8} R T$ is expected to vary depending on the characteristics of the signal. Thus, one might surmise that a predator sound or a mating call (both signals with high selective value to the animal) might have a lower $R T$ than the $R T$ of a non-threatening vocalization of another species.

${ }^{9}$ For example, the match filter output of a nominal vocalization that is $0.4 \mathrm{~s}$ in duration with $100 \mathrm{~Hz}$ of bandwidth could have a potential gain of $16 \mathrm{~dB}$ over a simple bandpass filter.
} 

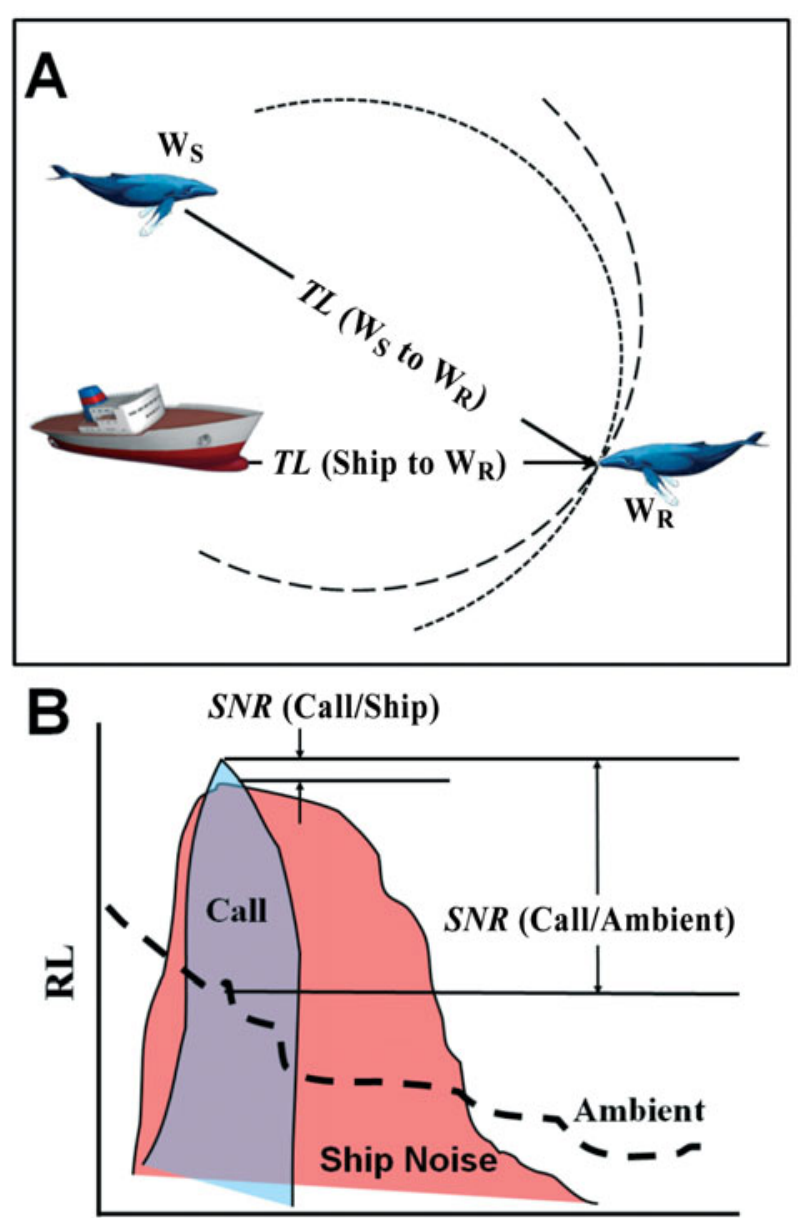

Frequency

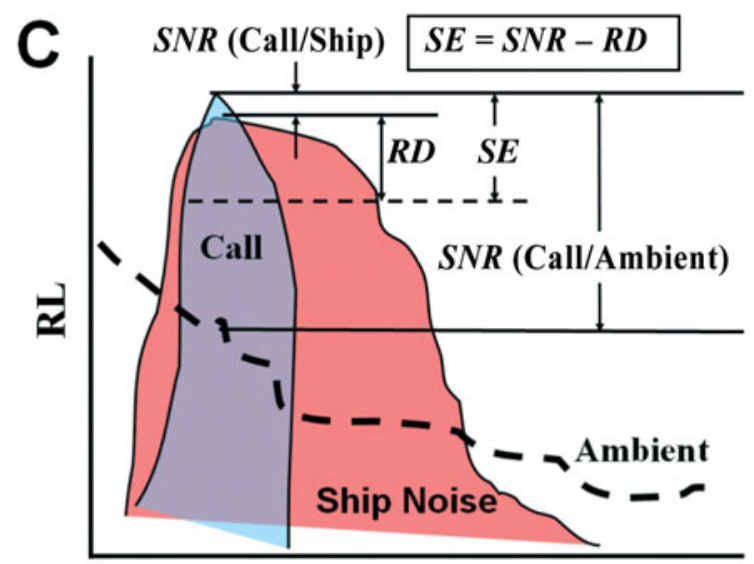

Frequency

Fig. 5. Masking of whale communication from shipping noise. The key communication masking components include: the ambient spectrum noise level at the receiving whale, $\mathrm{W}_{\mathrm{R}}$ the spectrum level of the call from the sending whale, $\mathrm{W}_{\mathrm{S}}$, at the receiving whale; the spectrum noise source level of the ship; and the received level of the ship noise at the receiving whale; the spectral distributions of the ambient noise, ship noise and whale call; and the transmission loss from the ship to the receiving whale [TL(ship to $\left.\left.\mathrm{W}_{\mathrm{R}}\right)\right]$ and from the calling whale to the receiving whale $\left[T L\left(\mathrm{~W}_{\mathrm{S}}\right.\right.$ to $\left.\left.\mathrm{W}_{\mathrm{R}}\right)\right]$ path effects that strongly influence the amplitude-time and frequency-amplitude structure of a signal. In essence, the level of a broadband signal at a receiver can be viewed as if it were sampled at a number of points over some distance interval relative to its distance from the source. As stated by Harrison \& Harrison (1995), a broadband signal of mean frequency $\left(f_{0}\right)$ and bandwidth $(W)$ can be viewed as if its $R L$ were sampled at a number of points over a distance interval $\left(R_{I N T}\right)$ relative to a distance $\left(R_{0}\right)$ such that

$$
R_{I N T}=R_{0}\left[W / f_{0}\right]
$$

This is tantamount to averaging the signal over its entire frequency band at a single, distant point. Signal bandwidth, therefore, minimizes peaks and largely removes spectral nulls that would otherwise be present in a pure tone transmission. The result is a signal that has a higher probability of being recognized. In biological terms, selection should favor animals with sensory perception and processing mechanisms that take advantage of signal bandwidth.

Including a recognition differential for conspecific communication modifies Eq. (4) for $S E$ to:

$$
\begin{aligned}
& S E=S L-T L-N L-D T+D I+S G \\
& \text { i.e. } \quad S E=S N R-D T+D I+S G
\end{aligned}
$$

Here we take into account 3 different scenarios for noise: (1) very quiet ambient noise conditions when there are no anthropogenic noise sources; a condition we refer to as 'ancient ambient' noise (AA), (2) ambient noise conditions as they typically occur in the present habitat but when there are no discrete anthropogenic noise sources ('present ambient', PrA1), and (3) noise conditions as a result of ancient ambient noise and a single or multiple discrete anthropogenic sources ('present noise sources', PrA2). Note that for all scenarios there are variable natural conditions such as wind speed and precipitation that can alter the value of ambient noise.

Using Eq. (9), rearranging, and taking Eq. (3) into account yields 3 different expressions for $S E$ at a receiver under the different noise conditions.

$$
\begin{gathered}
S E_{A A}=R L_{R}-D T+D I+S G-N L_{\mathrm{AA}} \\
S E_{\mathrm{PrA} 1}=R L_{R}-D T+D I+S G-N L_{\mathrm{PrA} 1} \\
S E_{\mathrm{PrA} 2}=R L_{R}-D T+D I+S G-N L_{\mathrm{PrA} 2}
\end{gathered}
$$

where $N L_{\mathrm{PrA} 2}=\sum_{1}^{n}\left(N S L_{n}-N T L_{n}\right)$, and $n$ is the number of different discrete noise sources.

Here the term $\left(R L_{R}-D T+D I+S G\right)$ defines the condition under which the signal could possibly be perceived by the receiver under ancient ambient noise conditions (i.e. $S E_{\mathrm{AA}}>0 \mathrm{~dB}$ ). We assume that this very quiet, ancient ambient noise condition defines the lowest noise condition (i.e. the noise 
floor) to which the animal's auditory system has evolved. Therefore, the value of $S E$ under the ancient ambient noise condition will be used as the standard by which to determine the relative area over which communication can take place under a present noise condition.

\section{Communication masking terms and algorithm}

Communication space for a single sender

There are at least 4 sub-sets within the term communication space for a single sender, and these are not mutually exclusive. These are:

(1) 'Potential communication space': the volume of space surrounding an individual within which acoustic communication with other conspecifics could occur under normally optimal conditions.

(2) 'Actual communication space': the volume of space surrounding an individual within which acoustic communication with other conspecifics actually occurs. Many of the features of actual communication space must be determined empirically, and there are few data quantifying actual communication space for any marine mammal.

(3) 'Sender communication space': the volume of space surrounding a sound producing animal within which acoustic communication with listening conspecifics could occur.

(4) 'Receiver communication space': the volume of space surrounding a listening animal within which conspecifics producing sounds could be recognized by that animal.

In all further discussion we simplify the dimensionality of communication space to be an area, while recognizing that it is actually a volume.

Fig. 6 illustrates Eq. (9a) assuming a normal mode transmission loss function (Porter \& Reiss 1985) for 2 different ambient noise levels; $81 \mathrm{~dB}$, representing the ancient ambient noise level in the right whale communication band and $96 \mathrm{~dB}$, representing an ambient noise level under present conditions. In these simplified cases, the communication space is the area of the circle in which $S E>0 \mathrm{~dB}$. This figure illustrates several important features of communication space: (1) the influence of transmission loss on the shape of the $S E$ curve; where TL is always dominated by logarithmic sound attenuation, (2) the resultant rapid fall off in $R L$, (3) the importance of $R D$ and $S G$ in the calculation of $S E$, and (4) the influence of noise level on the distance over which $S E>0$.

We assume that the area within which $S E>0 \mathrm{~dB}$ under ancient ambient conditions $\left(S E_{A A}\right)$ defines the space within which communication could possibly
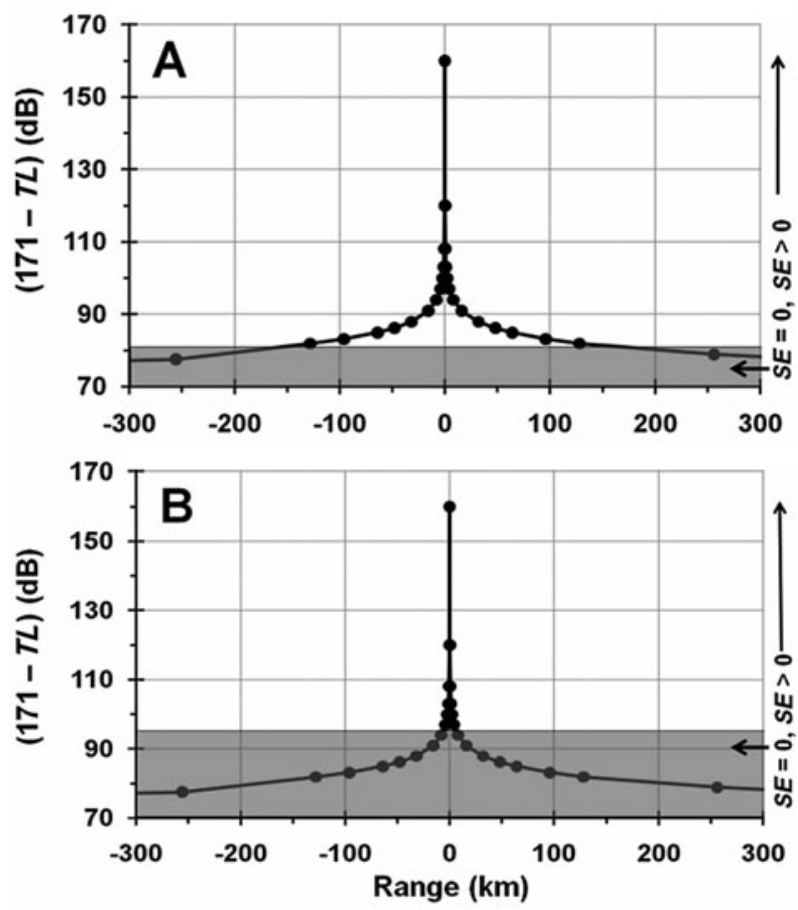

Fig. 6. Examples to illustrate the change in potential communication range for a low-frequency right whale call under 2 different levels of omnidirectional ambient noise ( $N L$, shaded) and assuming $S L=165 \mathrm{~dB}, D T=10 \mathrm{~dB}, S G=16 \mathrm{~dB}$, and $D I=$ $0 \mathrm{~dB}$ : (A) $N L=81 \mathrm{~dB}$, range $>300 \mathrm{~km}$, area $=210000 \mathrm{~km}^{2}$; (B) $N L=96 \mathrm{~dB}$, range $=6 \mathrm{~km}$, area $=113 \mathrm{~km}^{2} . T L=$ $20 \log [$ range $/ 1 \mathrm{~m}]$ for range $\leq 1 \mathrm{~km}$ and $T L=60 \mathrm{~dB}+$ $10 \log [\mathrm{range} / 1 \mathrm{~km}]$ for range $>1 \mathrm{~km}$. The arrow in the lower right points to the level at which $S E=0$. Note: absorption is not a factor for the frequencies and ranges considered here

occur. This potential communication space for a sender, $P C S_{S}$, can be discretely represented as:

$$
P C S_{S}=\sum_{i=1}^{R} f(S E)_{i} \cdot P R(S E)_{i}
$$

where $i$ is the total number of potential receivers, $R$, and

$$
f(S E)_{i}=0 \text { for } S E<0 \mathrm{~dB}, f(S E)_{i}=1 \text { for } S E \geq 0 \mathrm{~dB}
$$

For mysticete whales there are few to no measurements that can be used to define actual communication ranges. Bowhead, North Atlantic right and southern right (Eubalaena australis) whales have been observed counter-calling out to ranges of approximately $20 \mathrm{~km}$ (Clark 1983, Clark 1989, Clark unpubl. data), and fin whales and humpback whales are suspected of communicating out to distances of at least $10 \mathrm{~km}$ (Watkins \& Schevill 1979, Watkins 1981, Tyack 2008). Fin and blue whales (Balaenoptera musculus) have been detected, located and tracked out to ranges of many hundreds of kilometers (Clark \& Gagnon 2002, Watkins et al. 2004, Moore et al. 2006, Stafford et al. 2007). There is certainly the potential that these 2 species might communicate over many hundreds of miles 
(Payne \& Webb 19971), but this has not been demonstrated. If we assume that under ancient ambient noise conditions the communication range for fin, humpback and right whales is $20 \mathrm{~km}$, the communication space, $C S_{\text {Smax }}$ for these species would be $1258 \mathrm{~km}^{2}$.

However, this estimate of communication space does not account for the fact that as the distance between a sender and receiver increases and $S E$ approaches $0 \mathrm{~dB}$, the probability of the receiver recognizing the sender's signal decreases. To account for this uncertainty in the probability that communication actually occurs we weight the $S E$ values throughout the area by a probability-of-recognition term, $P R$; where $P R=0.5$ at $S E=$ $0 \mathrm{~dB}$, and $P R=1.0$ at $S E=18 \mathrm{~dB}$. The upper value of $18 \mathrm{~dB}$ is assumed based on analogy to recognition thresholds in human speech (Pearsons et al. 1977, Tafalla \& Evans 1997, Peters et al. 1999). We refer to this area weighted by a recognition function as a sender communication space. Under ancient ambient noise conditions we assume that a sender's communication space is maximized, with the 'maximum sender communication space', $C S_{\text {Smaxı }}$ represented as:

$$
P C S_{S}=\sum_{i=1}^{R} f(S E)_{i} \cdot P R(S E)_{i}
$$

where $i$ is the number of receivers,

$f(S E)_{i}=0$ for $S E<0 \mathrm{~dB}, f(S E)_{i}=1$ for $S E \geq 0 \mathrm{~dB}$,

$P R(S E)_{i}=0.5+\frac{(1-0.5)}{18} \cdot S E_{i}$ for $0 \mathrm{~dB} \leq S E<18 \mathrm{~dB}$, and $P R(S E)_{i}=1$ for $S E \geq 18 \mathrm{~dB}$.

This term $C S_{S \max }$ is important because it provides a measure of communication masking relative to a standard. Without a standardized reference, one loses the immense benefit of comparative evaluation, and a value of communication space obtained without that reference has little to no meaning. Thus, for example, when stating that a noise source reduces an animal's communication space by $30 \%$, that $30 \%$ needs to be relative to some standardized communication space. $C S_{\text {Smax }}$ serves as the standard reference against which changes in a sender's communication space under different ambient noise conditions can be compared. Its value depends, in part, on the source level of the sound produced by the sending whale and the environmental conditions under which that signal could propagate to potential receivers under a standardized ambient noise condition. We propose that ancient ambient noise be used as the standard noise condition for calculating maximum communication space. We propose that the level of the 5th percentile order statistic (in the communication frequency band), based on the analysis of a significant acoustic sample, be used as a reference level for ancient ambient noise, where at least a month of data under present conditions is considered a significant acoustic sample. This level assumes that the 5th percentile order statistic value does not include appreciable contributions from shipping. By this procedure any change in communication space as a result of present ambient noise levels and/or specific noise sources is quantified relative to a pre-industrial noise level.

So far we have only presented examples with different levels of ambient noise, but without inclusion of specific noise sources such as ships. When specific noise sources with spatial and temporal properties are considered, the noise level surrounding a receiver is dynamic and varies over space and through time. That is, the term $N L_{\mathrm{PrA} 2}$ in Eq. (10c) is a function of time and the relative positions of the receiver and the noise source(s). Given these considerations and the background examples (Figs. 5 \& 6), what can we say about how much a ship might mask the signal from a sending whale at a receiving whale? By using propagation equations to estimate both the $R L$ of the sound from the calling whale and the $R L$ from the ship at the receiving whale, and by using these values in Eq. (10), we can determine the $S E_{\mathrm{PrA} 2}$ at the receiving whale during the brief moment in time when the whale called. If the $S E_{\mathrm{PrA} 2}<0$, we could say that the noise from the ship masked the sound from the sending whale. However, even for this static case, this evaluation does not actually provide a full measure of the communication masking effect of the ship because it does not include the total reduction in the calling whale's communication space as a result of the ship's passage. To adequately quantify communication masking over the potential communication space of the calling animal one must include a representative sample of possible receiving whales throughout the period of time when the noise source could interfere with communication.

To do this, we calculate a sender's communication space under a present noise condition, $C S_{S}$ by considering a single sending animal and a grid of possible receiving animals, uniformly distributed over an ecologically meaningful area ${ }^{10}$; where

$$
C S_{S}=\frac{\sum_{i=1}^{R} f(S E)_{i} \cdot P R(S E)_{i}}{C S_{S \max }}
$$

The term $C S_{S}$ represents the portion of the communication space (i.e. a value between 0 and 1 ) available to a sender under the existing noise conditions relative to maximum sender communication space under an ancient ambient noise condition. To estimate temporal variation in the communication space for a single sender over a given time period, we calculate $C S_{S}$ values at regular time intervals.

\footnotetext{
10In terms of acoustic ecology, an ecologically meaningful area is one in which the spatial dimensions of the area are at least on the same order of magnitude as twice the communication range of the species under consideration.
} 
Communication space for multiple senders

The 'maximum communication space for multiple senders', $C S_{M S \max }$ in an ecologically meaningful area is calculated based on the sum of all the maximum sender communication spaces for each individual in that area.

$$
C S_{\text {MSmax }}=\sum_{j=1}^{M}\left(C S_{\text {Smax }}\right)_{j}
$$

where $M$ is the number of senders, and the 'multiplesender communication space', $C S_{M S}$ relative to ancient ambient noise condition is:

$$
C S_{M S}=\frac{\sum_{j=1}^{M}\left(C S_{S j}\right)}{C S_{M S \max }}
$$

To estimate temporal variation in the communication space for multiple senders over some time period, the $C S_{M S}$ values are calculated at regular time intervals. The spatial mapping of the $C S_{S j}$ values for each of the $M$ senders at a single time interval shows the spatial distribution of communication space for the multiple senders, while the time series of communication space measures plotted at regular time intervals reveals the temporal variability of the communication space for the multiple senders.

'Communication masking' is the relative amount of change in an animal's acoustic space caused by the presence of interfering sound(s). The metric for communication masking is a measured change in acoustic space under a present condition relative to a standard condition. We propose that the basic standard condition be referenced to ancient ambient noise, while a secondary standard condition could be referenced to a present ambient noise condition that does not contain the noise source being measured.

'Masking of sender communication space' is the relative amount of change in a sender's communication space caused by the presence of interfering sound(s). The metric for sender communication masking is calculated as the relative difference between sender communication masking under ancient ambient noise conditions (our standard reference, as described above) and a present noise condition. By this definition and process, we will now calculate communication masking (1) for a single sending individual and multiple sending individuals, (2) for 3 different species-specific spectral bands, and (3) for a single noise source and multiple noise sources over different time samples.

Given all these considerations, the basic metric for communication masking is the portion of the potential communication space that is unavailable for communication. We refer to any such communication masking metric as a communication masking 'index' or an 'index of communication masking'. Thus, the communication masking index for a sender, $M_{S}$, for any particular time sample, $t$, is:

$$
\left(M_{S}\right)_{t}=\left(1-C S_{S}\right)_{t}
$$

The communication masking index for multiple senders, $M_{M S}$, for any particular time sample, $t$, is:

$$
\left(M_{M S}\right)_{t}=\left(1-C S_{M S}\right)_{t}
$$

The communication masking index for multiple senders over some period of time sampled at regular interval $T$ is the average value of $M_{M S}$ for $T$ samples:

$$
M_{T}=T^{-1} \sum_{t=1}^{T}\left(M_{M S}\right)_{t}
$$

In all further discussion of communication space and communication masking index, their calculated values as presented in figures will be given as a proportional number between 0 and 1 , while their values as enumerated in the text will be given as a percentage between 0 and 100 .

\section{Empirical measures of communication masking}

The following illustrate our methods for calculating communication space for a single sender and for multiple senders. For calculations of communication space we set $D T=10 \mathrm{~dB}^{\underline{11}}, D I=0 \mathrm{~dB}$, and $S G=16 \mathrm{~dB}^{\underline{12}}$. Thus, the combination of a $D I$ value that does not include any benefit from directionality in radiated sound or received sound and a modest value for $S G$ results in a negative $R D$ value, implying that in some circumstances animals have the ability to hear some sounds that are below the ambient noise level. For our empirical habitat, we use the Stellwagen Bank National Marine Sanctuary (SBNMS), an environment for which we have oceanographic data (i.e. bathymetry, seasonal sound velocity profiles), marine mammal data (i.e. acoustic locations and tracks of vocally active whales), and commercial shipping data (i.e. tracks, speeds, and source levels of ships moving through the area). We use 2 different areas centered on the SBNMS (Fig. 7). The first area contains all potential senders and is bounded by a circle whose radius is the distance within which the species is assumed to communicate under ancient ambient conditions (i.e. $20 \mathrm{~km}$ ). This area is gridded into a matrix of $4 \mathrm{~km}^{2}$ cells, with one sending

\footnotetext{
$\underline{11} 10 \mathrm{~dB}$ is an appropriate value for $D T$ in sonar systems as well as marine mammals (e.g. Kastelein et al. 2007)

12 This nominal value of $16 \mathrm{~dB}$ follows the logic presented in Clark \& Ellison (2004) and represents a time-bandwidth product (TW) of 40 . We recognize that using $16 \mathrm{~dB}$ for $S G$ is an over-simplification and that the value of this term is at least a function of the species and the communication context. Thus, for example, we would expect a humpback listening for humpback song with a $10 \mathrm{~s}$ phrase duration and $3 \mathrm{kHz}$ bandwidth to have a higher $S G$ than a right whale listening for a $1 \mathrm{~s}$ long, $100 \mathrm{~Hz}$ bandwidth right whale contact call.
} 


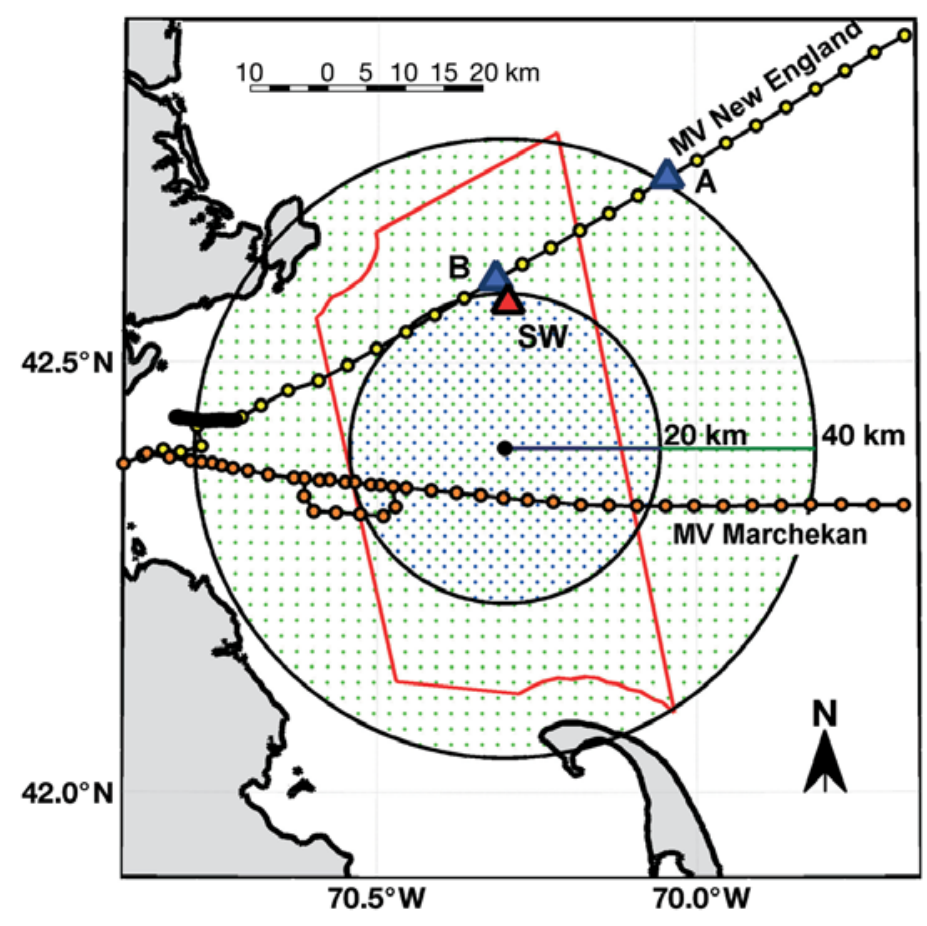

Fig. 7. Distribution of multiple sending whales $(\mathrm{n}=313$, dark blue dots) distributed over a circular area of diameter $=40 \mathrm{~km}$ and the distribution grid of possible receiving whales ( $\mathrm{n}=$ 1239, light green dots) distributed over a circular area of diameter $=80 \mathrm{~km}$. Also shown are the tracks of 2 commercial vessels, the MV 'New England and the MV 'Marchekan', which transited through the area on 27 December 2007 (see Fig. 3). The positions of the MV 'New England' are marked (blue triangles) at (A) 04:40 $\mathrm{h}$, when about to enter the receiving whale area, and (B) 05:40 h, when close to and northwest of a single sending whale, SW (red triangle), used in the examples of sender communication space. The red multisided box identifies the boundary of the Stellwagen Bank National Marine Sanctuary. (The trapezoidal track for MV 'Marchekan' occurred when the vessel made a counterclockwise loop to delay its entrance to Boston Harbor)

whale per cell. The second area contains all potential receivers and is bounded by a circle whose radius is equal to twice the species' communication range. This area is also gridded into $4 \mathrm{~km}^{2}$ cells, with one sending whale per cell. The 2 matrices are offset and interlaced such that, in the inner circle, there is a sender in the center of each receiver's $4 \mathrm{~km}^{2}$ cell, and there is a receiver in the center of each sender's $4 \mathrm{~km}^{2}$ cell. By this procedure there are 316 receivers in each sender's space and a total of 313 senders (i.e. $i=316$ and $j=$ 313). In all these analyses the ancient ambient band level noise value is $75 \mathrm{~dB}$ for fin, humpback and right whales.

In the following 3 examples we calculate and show the sender communication space for (1) a single calling right whale, a species in which whales counter-call to maintain contact and initiate social interactions (Clark 1983, Clark et al. 2007, Parks et al. 2007); (2) a singing
Table 3. Species-specific sound parameters used in calculations of communication space. 'Band (Hz)' is the low-high frequency range for the set of 1/3rd-octave bands used to calculate RLs. SRD: 'Source-receiver depths', the depth of the calling and listening whales. $C R$ : 'Communication range', the maximum distance out to which whales are assumed to communicate

\begin{tabular}{|lccccccc|}
\hline Species & $\begin{array}{c}\text { Band } \\
(\mathrm{Hz})\end{array}$ & $\begin{array}{c}S L \\
(\mathrm{~dB})\end{array}$ & $\begin{array}{c}D T \\
(\mathrm{~dB})\end{array}$ & $\begin{array}{c}D I \\
(\mathrm{~dB})\end{array}$ & $\begin{array}{c}S G \\
(\mathrm{~dB})\end{array}$ & $\begin{array}{c}S R D \\
(\mathrm{~m})\end{array}$ & $\begin{array}{c}C R \\
(\mathrm{~km})\end{array}$ \\
\hline Fin & $18-28$ & 180 & 10 & 0 & 16 & 20 & 20 \\
Humpback & $224-708$ & 170 & 10 & 0 & 16 & 20 & 20 \\
Right & $71-224$ & 160 & 10 & 0 & 16 & 20 & 20 \\
\hline
\end{tabular}

fin whale and a singing humpback whale, species in which males produce long sequences of intense sounds that function as male reproductive displays (Payne \& McVay 1971, Watkins et al. 1987, Croll et al. 2002), and for a single calling right whale; and (3) multiple senders for all 3 species.

We use the Acoustic Integration Model $^{\circledR}$ (AIM; Ellison et al. 1999, Frankel et al. 2002) to calculate received levels of sound from a sender at each receiver $\left(R L_{R}\right)$ in a grid of possible receiver locations, and the $R L \mathrm{~s}$ of sound from known noise sources (e.g. ships) for that same receiver grid. We begin with a single noise source (the MV 'New England', see Fig. 7) and consider the species-specific parameters used in these analyses (Table 3) as illustrated by spectrographic examples of the species-specific sounds (Fig. 8).

Fig. 9 illustrates the sender communication space for a single calling right whale at 2 different times when the commercial vessel MV 'New England' was moving through the whale's acoustic space. In this case, the 316 hypothetical receiver whales in the communication space are divided into whales for which $S E>0 \mathrm{~dB}$ (light grey dots) and $S E \leq 0 \mathrm{~dB}$ (dark grey dots). In Example 1, when the ship is outside and approaching the sender communication space, the ship noise results in a $6 \%$ decrease $(19 / 316)$ in the number of receivers for whom $S E>0 \mathrm{~dB}$, or, in our terminology, a $6 \%$ decrease in sender communication space; later, at 05:40 $\mathrm{h}$, when the ship is inside the sender communication space, the ship noise results in a $97 \%$ decrease (306/316) in the sender communication space.

Fig. 10 shows the sender communication spaces, $C S_{S}$, for a single fin, humpback and right whale located in the center of the gridded receivers $(n=316)$ at 2 times (04:40 and 05:40 h) as the MV 'New England' was moving into and through the area. The source levels of the ship in the fin, humpback and right whale frequency bands were 181, 167 and $172 \mathrm{~dB}$, respectively. Here the sender communication space for each of the 316 receiver whales is coded by the $\mathrm{dB}$ value of $f\left(S E_{i}\right) \cdot P R\left(S E_{i}\right)$ (see Eq. 12). 


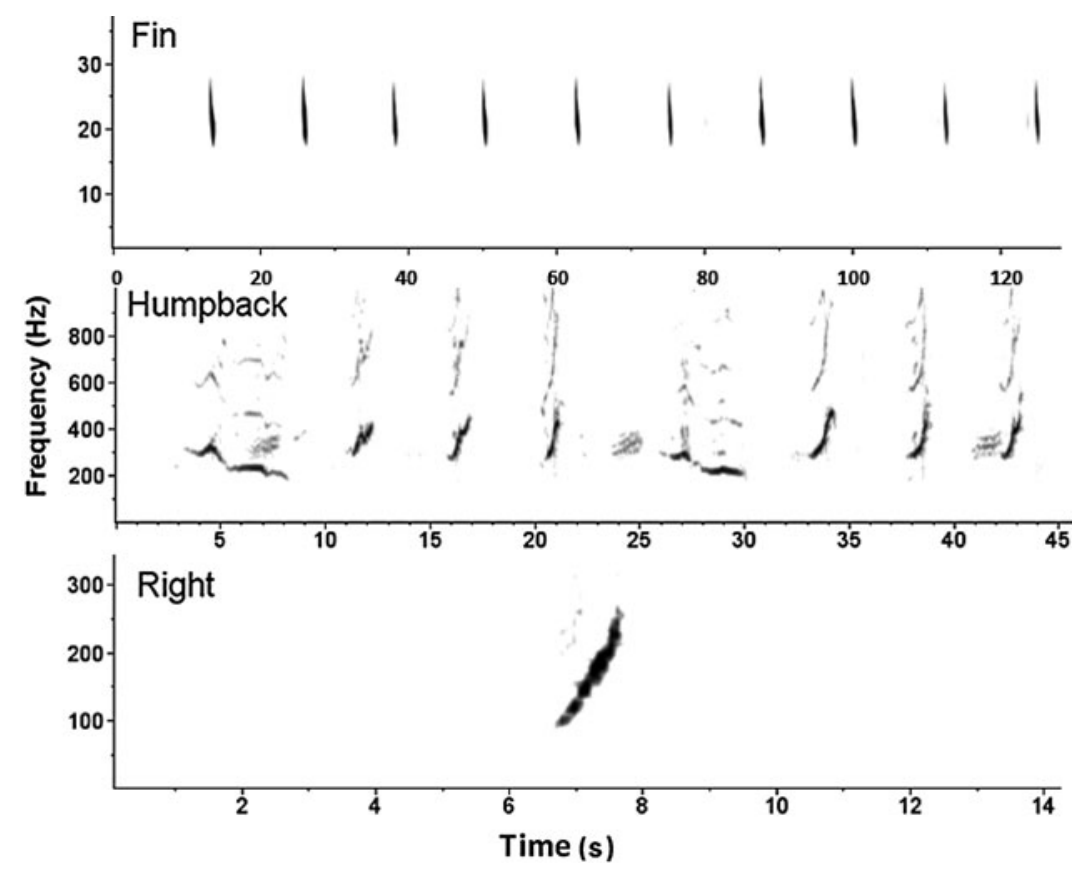

Fig. 8. Spectrogram examples showing the repetitive, cadenced features of fin whale song (top); the repeated, syllabic, but subtly variable features of humpback whale song (middle); and the simple, glissando features of a right whale contact call (bottom) [1024 pt FFT, 50\% overlap, Hanning window]. Note the different frequency ranges and durations for each of the species

for the $12 \mathrm{~h} 20$ min time period during which MV 'New England' approached, moved through, and departed from the communication area (Fig. 13).

The communication spaces for the fin and humpback whale singers were only slightly changed by the passage of the ship and only for the short period of time when the ship was very close to the receiving whales. In contrast, the right whale communication space was dramatically reduced throughout most of the time that the ship was passing through the area.

One very important outcome from the development of this algorithm, and illustrated by these analytical examples, is that we now have a comparative metric to quantify these differences and variations in communication space for individuals and groups of calling animals throughout a habitat and over a selected period of time. Thus, in the example above when considering a single singing fin, singing humpback or calling right whale located in the center of the $1239 \mathrm{~km}^{2}$ potential CS (Figs. 10 \& 11), the sender $C S$ for each species during

Time-varying communication space values of $C S_{S}$ can be calculated over a portion of the day (27 Dec 2007) for each of the 3 species (Fig. 11). These represent the percentage of the communication space available to the sender throughout the $12.3 \mathrm{~h}$ period as MV 'New England' approached, moved through, and departed from the communication area.

These 2 examples demonstrate how the communication space for a single sending whale can vary depending on (1) the proximity of the noise source, (2) the noise level of the noise source in the species-specific frequency band, (3) the source level of the whale's communication sound, and (4) the frequency band of the whale's communication sound.

Fig. 12 shows multiple sender communication spaces $\left(C S_{M S}\right)$ for 313 hypothetical fin whale singers, humpback whale singers and calling right whales calculated (see Eq. 15) at the same 2 times when the MV 'New England' was moving through the acoustic spaces for each of the 3 different species. The time-varying values of communication space for each of these hypothetical sets of fin whale singers, humpback whale singers and calling right whales can be calculated at regular intervals
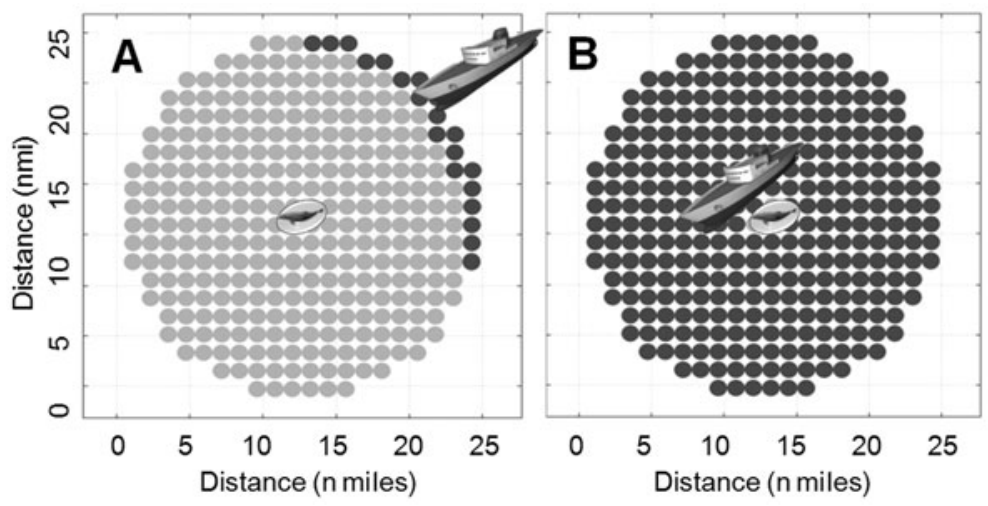

Fig. 9. Spatial distribution of sender $C S$ for a grid of uniformly distributed receivers $(n=316)$ based on a calling right whale in the center of the space $(S L=160 \mathrm{~dB}, D T=-10 \mathrm{~dB}, S G=16 \mathrm{~dB})$ and for the noise from the vessel MV 'New England' $(S L=172 \mathrm{~dB})$, (A) approaching the sender from the northeast (see Figs. $3 \& 7$ ), and (B) when the ship was $4 \mathrm{~km}$ northwest of the sender. Light dots: receivers for which $S E>0 \mathrm{~dB}$; dark dots: receivers for which $S E \leq 0 \mathrm{~dB}$ 

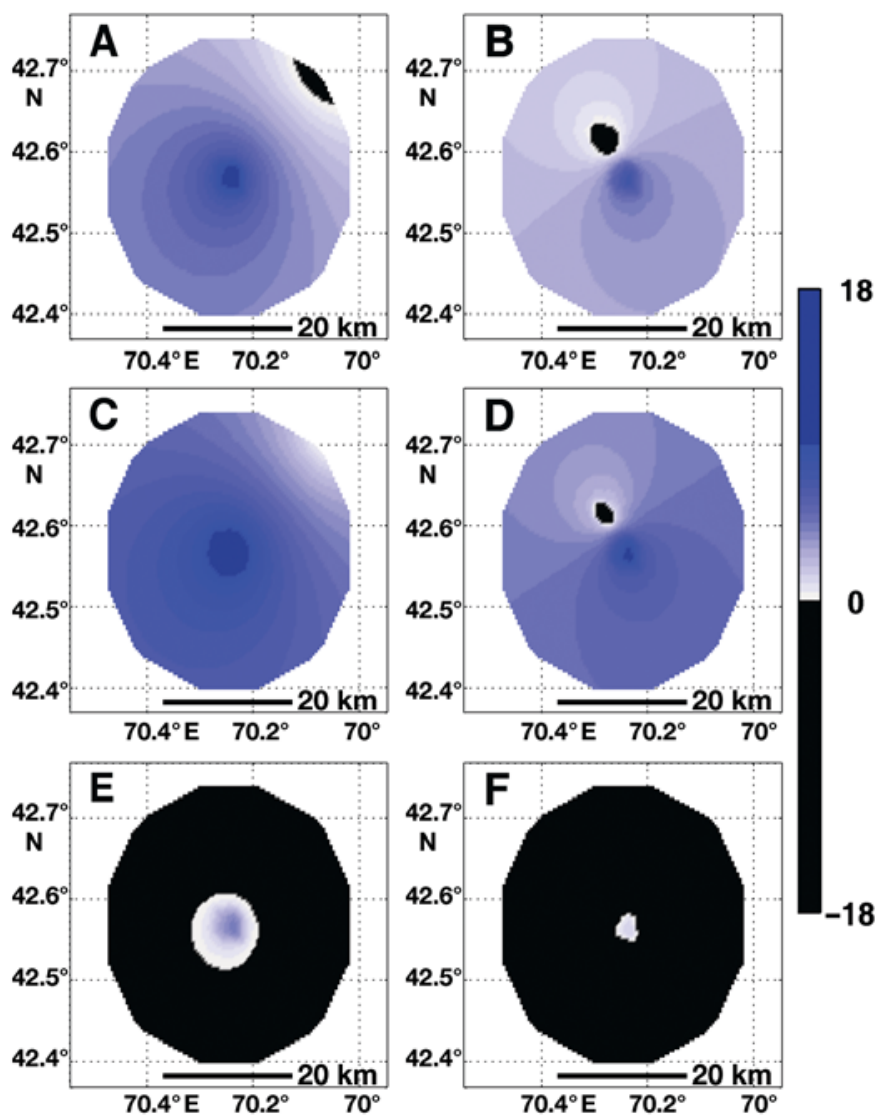

Fig. 10. Spatial distributions of sender $C S$ for a single fin whale singer $(A, B)$, humpback whale singer $(C, D)$ and calling right whale $(\mathrm{E}, \mathrm{F})$ as a function of noise from an approaching ship, the MV 'New England'. The sending whale is located in the center of a $1256 \mathrm{~km}^{2} C S$ of 316 receiving whales. Left hand panels are at 04:40 $\mathrm{h}$ when the ship was northeast of the sender. Right hand panels are at 05:40 h when the ship was $\sim 4 \mathrm{~km}$ northwest of the sender. The scale bar indicates the recognition-weighted value of $S E$ in $\mathrm{dB}$ at the receiver locations (Eq. 12)

MV 'New England' was approaching and transiting through that area, the average percentage of individual sender $C S$ available was $80 \%(\mathrm{SD} \pm 7 \%$ ) for fin whales, $92 \%$ (SD $\pm 6 \%$ ) for humpback whales, and $23 \%(\mathrm{SD} \pm 16 \%)$ for right whales.

These examples indicate that calling right whales are predicted to have been affected to a much greater extent by masking noise from the MV 'New England' on 27 Dec 2007 than either singing fin or singing humpback whales. In fact, the percentage of sender $C S$ available to a uniformly distributed set of calling right whales at this time was estimated to be 3.8 times less than that for singing humpbacks. During this par-

$\underline{13}$ Values of $C S$ and $M$ for receiving individuals or populations are similarly derived but are not the same as for sending animals. ticular $12.33 \mathrm{~h}$ period, noise from MV 'New England' resulted in average percentages of communication masking for fin, humpback and right whales of $19 \%$ $(\mathrm{SD} \pm 0.06), 8 \%(\mathrm{SD} \pm 0.05)$, and $76 \%(\mathrm{SD} \pm 0.17)$, respectively (Fig. 14).

Because the masking algorithm index is generalized (Eq. 10c), we can accumulate additional noise sources in the calculation of $M$. Thus, for example, when masking noise from a second ship (MV 'Marchekan', 14:50 to $20: 50 \mathrm{~h}$; see Fig. 7 ) is added to the noise from MV 'New England', the accumulated noise during the $21 \mathrm{~h}$ period $(01: 10 \mathrm{~h}$ to $22: 10 \mathrm{~h})$ increases the average percentages of communication masking for fin, humpback and right whales to $33 \%(\mathrm{SD} \pm 0.14), 11 \%(\mathrm{SD} \pm 0.06)$, and $84 \%$ ( $\mathrm{SD} \pm 0.16)$, respectively (Fig. 15).

\section{DISCUSSION}

Ocean ambient noise and noise sources mask the communication sounds of free-ranging marine mammals. A mechanism is described for quantitatively assessing communication masking for one or many sending animals as a result of one or more noise sources ${ }^{13}$. Here the term communication masking is a modification of the term as originally developed for human speech. In the clinical sense, communication masking is the amount (or process) by which the threshold of audibility of one sound is raised by the presence of another (masking) sound (Tanner 1958, Moore 1982). We redefine the term communication masking for the practical situation in which free-

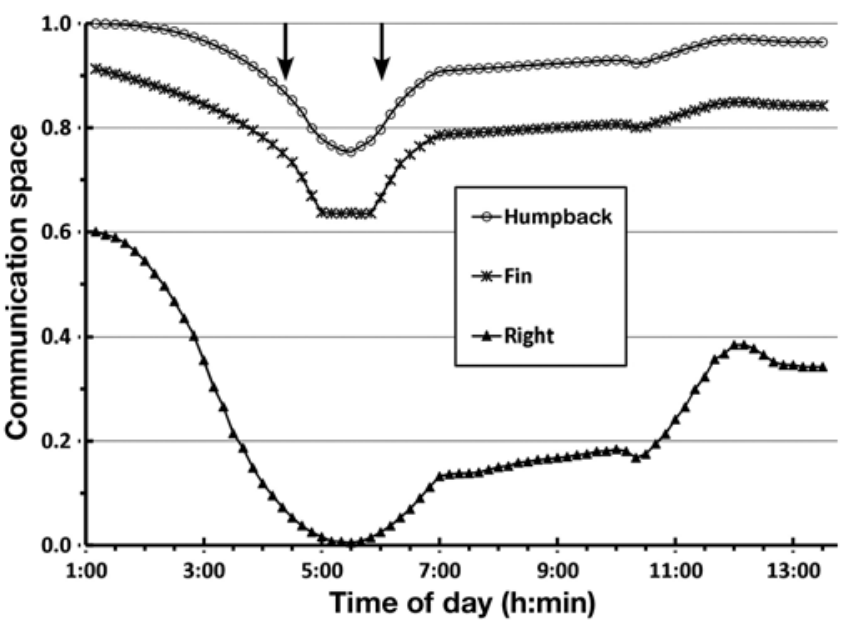

Fig. 11. Time-varying percentages of $C S_{S}$ (Eq. 13), as a function of ship noise, for a single fin whale singer, humpback whale singer and calling right whale during the passage of MV 'New England' through the SBNMS on 27 December 2007. Samples were taken every $10 \mathrm{~min}$ from $01: 10$ to $13: 30 \mathrm{~h}$. The 2 arrows correspond to the 2 sample times (04:40 and 05:40 h) shown in Fig. 10 

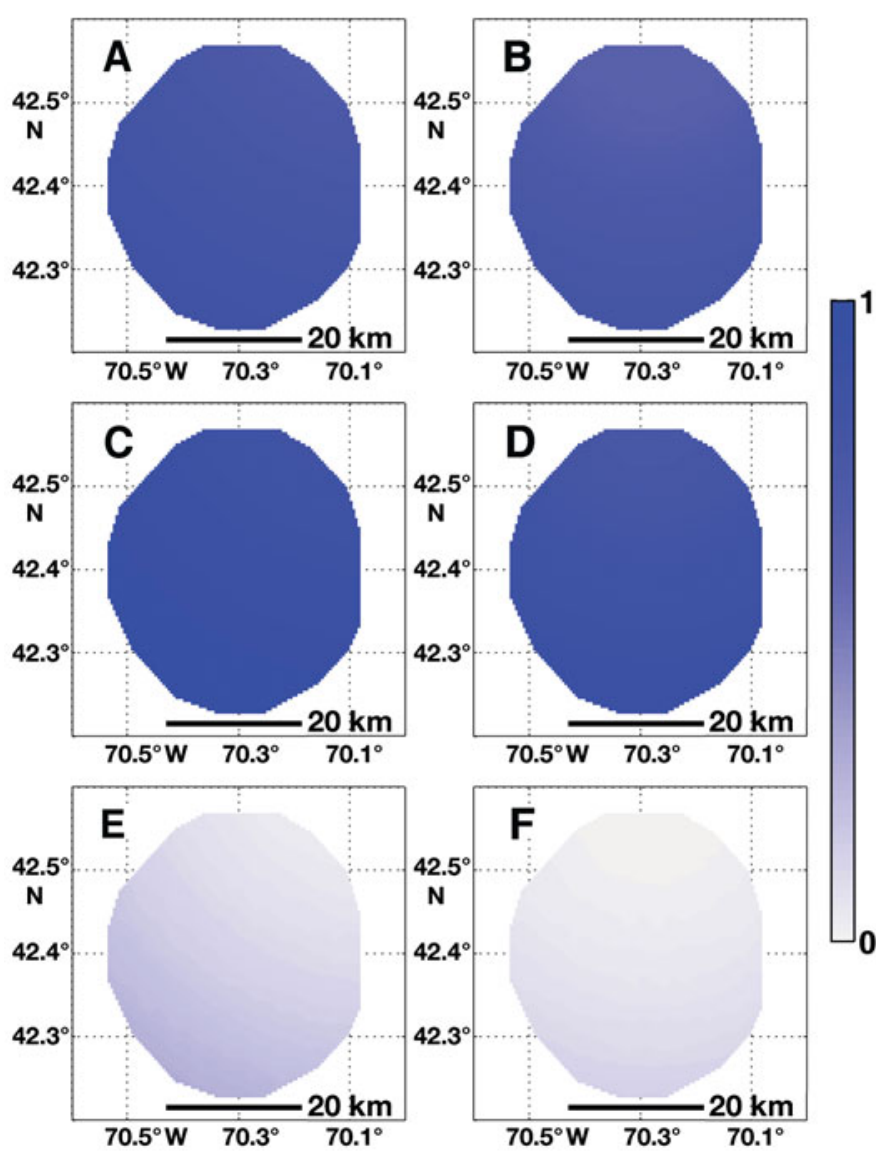

Fig. 12. Spatial distributions of $C S$ for a uniformly distributed number of fin whale singers, humpback whale singers and calling right whales $(\mathrm{n}=313)$ and for noise from an approaching ship, the MV 'New England'. Left-hand panels are at 04:40 h when the ship was $\sim 40 \mathrm{~km}$ to the northeast of the closest sender, and right-hand panels are at $05: 40 \mathrm{~h}$ when the ship was $\sim 4 \mathrm{~km}$ to the northwest of the closest sender (see Figs. 3 \& 7). (A, B) fin whale; (C, D) humpback whale; (E, F) right whale. Scale bar indicates the $C S_{M S}$ value (see Eq. 15)

ranging marine mammals are communicating under the acoustic conditions present within their existing habitats. Under this real-world context, communication masking is measured as a loss of communication space as a result of other sound(s), either natural or anthropogenic, relative to that space under quiet ancient ambient conditions; where we use the 5th percentile noise level as that reference for quiet noise.

We have merged the well established and empirically-based knowledge of ocean acoustic propagation modeling and the sonar equation, and informed these with empirical biological parameters and biological considerations relative to space, frequency and time. By tuning these parameters to the actual bioacoustic characteristics of communication sounds for different species we calculate measures that quantify the spatiospectral-temporal variability of a species' communica- tion space in real-world conditions involving human sound sources. The result is a metric by which one can systematically measure and compare changes in communication space as a result of anthropogenic sound(s); in the case here, the noise from a commercial ship moving through a marine sanctuary in which at least 3 species have seasonal residence.

We demonstrate that it is possible to assign objective, quantitative values to the communication masking of free-ranging marine mammals operating in the presence of real-world anthropogenic noise sources, and to provide insight into the potential effects of communication masking by ship noise on fin, humpback and right whales in an important coastal habitat. This process can be expanded and applied to other species, in other biological contexts, in other habitats, and on different spatial and temporal scales.

Communication masking by ship noise is much more severe for calling right whales than it is for singing fin or humpback whales in the examples considered here (see Figs. 13 to 15). In these analyses a major reason for this difference is source level: right whale calls are not as loud as fin or humpback songs. Combined with differences in source level are the differences in the species-specific, noise band levels from the ship; 181, 167, and $172 \mathrm{~dB}$ for fin, humpback and right whales, respectively (NSL re $1 \mu \mathrm{PA} @ 1 \mathrm{~m})$ and the different transmission losses for the noise in those different frequency bands. What is not considered here is source level variability; right whales certainly do not always call at $160 \mathrm{~dB}$ or fin whales at $180 \mathrm{~dB}$; or the actual variability in a species' recognition threshold, which we have simplified by assuming that all 3 species have a

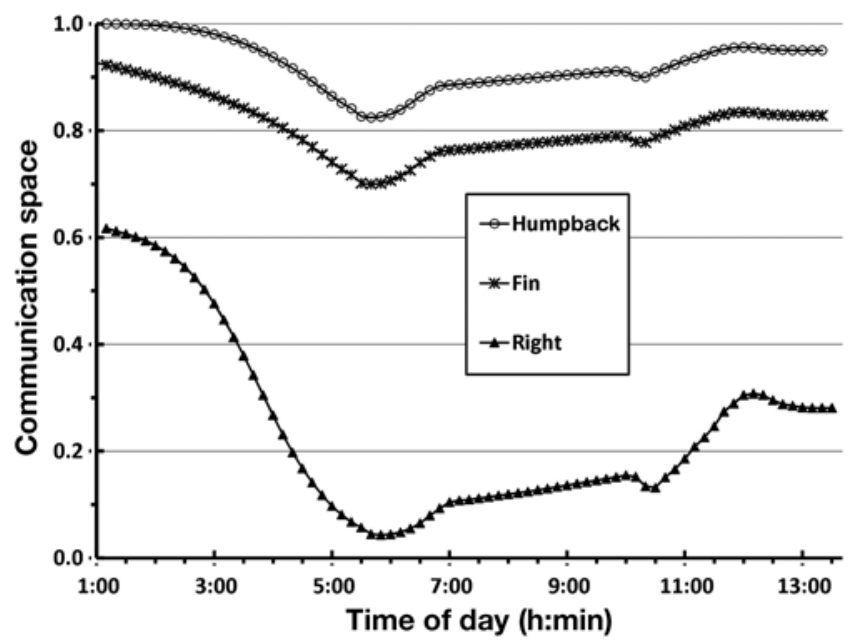

Fig. 13. Time-varying percentages of $C S_{M S}$ (Eq. 15) available for a uniformly distributed number of fin whale singers, humpback whale singers and calling right whales $(n=313$, see Fig. 12) on 27 December 2007. Samples taken every $10 \mathrm{~min}$ from $01: 10$ to $13: 30 \mathrm{~h}$ 


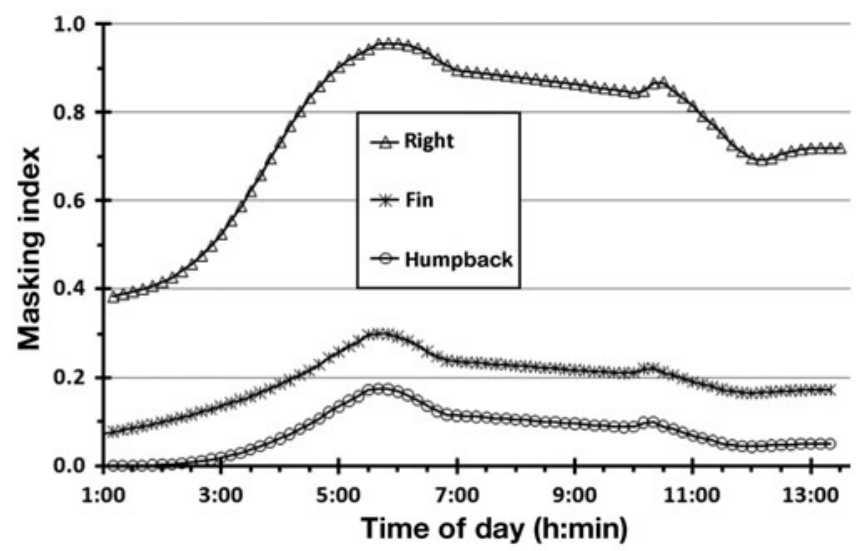

Fig. 14. $M$ for a uniformly distributed number of fin whale singers, humpback whale singers and calling right whales (see Fig. 12 \& 13) on 27 December 2007 as a result of noise from the MV 'New England'. Samples were taken every 10 min from $01: 10$ to $13: 30 \mathrm{~h}$

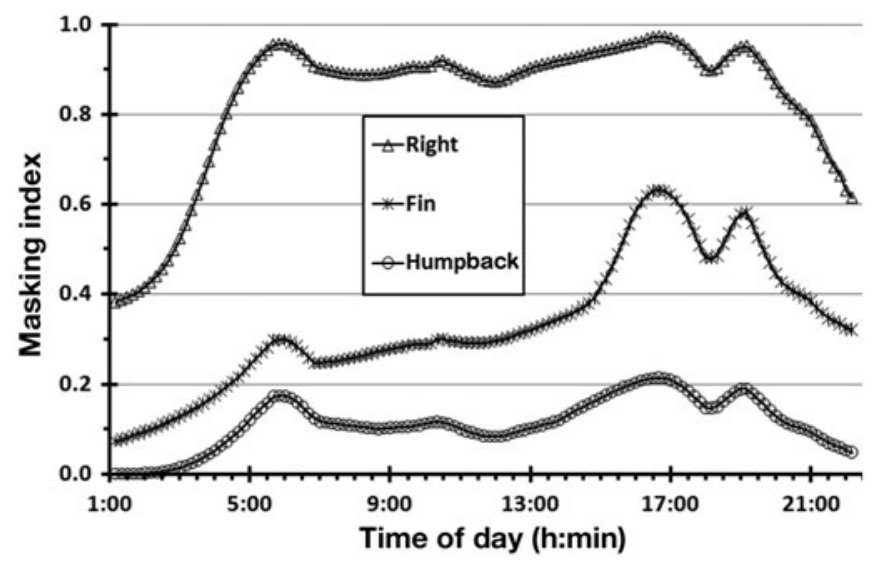

Fig. 15. Cumulative $M$ for a uniformly distributed number of fin whale singers, humpback whale singers and calling right whales (see Fig. 14) on 27 December 2007 as a result of noise from 2 ships, the MV 'New England' and the MV 'Marchekan'. Samples were taken every $10 \mathrm{~min}$ from 01:10 to 22:10 h

signal processing gain of $16 \mathrm{~dB}$; or the areas over which these animals actually communicate, which we have simplified by assuming that all 3 species only communicate out to a range of $20 \mathrm{~km}$.

These basic considerations emphasize the need to know more about the characteristics of communication signals, the conditions under which animals actually produce these signals, and how they might vary their communications under different contexts. Almost every term and parameter is a function of multiple variables, and the variance in each of these variables imposes different amounts of uncertainty on the outcome of any estimate of communication masking. However, these uncertainties are bounded and their simplification allows one to calculate estimates that are at least good first order approximations. There- fore, these estimates are useful for assessing the potential for communication masking on different whale species.

Knowing the biological and abiotic parameters (e.g. frequency band, integration time, communication range, call source level of animal's sound, depth of calling and receiving animals, anthropogenic noise source characteristics and movements, propagation loss features) one can envision how noise might mask the communication space of a roving herd of pilot whales whistling in the $7-12 \mathrm{k} \mathrm{Hz}$ band at $175 \mathrm{~dB}$ ( $S L$ re $1 \mu \mathrm{Pa} @ 1 \mathrm{~m})$. Given the much higher transmission loss and lower source levels of ships at these frequencies as well as the expected smaller communication space for pilot whales under normally quiet conditions, one might predict that the spatio-spectral-temporal footprint of communication masking from the ship noise on pilot whales would be much smaller than that for the baleen whales. The benefit from the algorithm presented in this paper is that it provides an analytical process by which to quantify what is meant by 'much smaller'.

Our considerations can be extended to non-continuous sources of noise (e.g. the low-frequency energy from seismic airgun arrays or construction activities) and acoustic contexts other than communication (e.g. echolocation or predator avoidance). A conclusion that is common to all, and independent of species or context is that the greatest uncertainties in our abilities to estimate the impacts of communication masking come from our ignorance of the spatial and temporal scales over which animals engage in their bioacoustic activities. Fairly little is known about the ranges over which the large whales actually communicate, although based on signal and receiver characteristics some estimates of communication distances are possible. However, without better knowledge certain assumptions about communication range are required and the resultant uncertainties in estimates of communication masking are dependent on those assumptions.

An important outcome (exemplified in Fig. 15) is that this communication masking algorithm can be used to evaluate the contributions to masking from individual sound sources and the cumulative effect of multiple sources on one or many individuals. Cumulative impact has been a long-standing, seemingly intractable issue in the debate over noise effects on marine mammals. Here we have presented a standardized metric to quantitatively estimate how much each sound source contributes to the communication masking index. Stated from an ecological perspective, we now have a measure for estimating the cost to communication, measured and expressed over ecologically meaningful spatial and temporal scales, for an individual or a population as a result of a particular sound source. Thus, 
using right whales as an example, we have shown that for at least $13.2 \mathrm{~h}$ of one day in the SBNMS the average communication masking index was 0.84 , or the cost to communication from 2 commercial ships was an $84 \%$ reduction of communication space, i.e. on average only $16 \%$ of a whale's expected communication space was available. Based on data in Hatch et al. (2008) indicating an average of 6 commercial vessels per day over a 2 mo period, we can assume that this magnitude of impact on potential right whale communication space occurs for much of the time that whales are in that habitat. This raises specific questions as to the cost to an individual right whale from this chronic noise condition and how the loss of communication opportunities might lead to decreased fecundity and rates of survival. At present we can only speculate because we do not know enough of the details about when and how the whales use their calls to communicate relative to the behavioral and ecological contexts, and how reductions in these capabilities translate into biological cost. We do know that these whales counter-call and use these episodes of calling to find each other and to aggregate, so one immediate cost is the loss of opportunities to form social groups. Right whales form aggregations during mating and during feeding, so one likely cost is the loss of mating and feeding opportunities. However, we do not yet know the real cost to an individual or a population from these lost opportunities.

The application and extension of the communication masking metric to quantify biological cost within an ecological framework offers a critical missing link to the major current dilemma of assessing noise impacts in the marine environment. As represented by the Potential Consequences of Acoustic Disturbance (PCAD) model (NRC 2005), there is a cascade of transitions between 5 core components in the model starting with physical acoustics and ending with population level effects. Each transition between model components shows the output(s) from one component as the input(s) into the next and then assumes that a response in the next component is a function of the input(s). The model provides no specific enlightenment as to how the transitions between components occur, or what the transfer functions are. In fact, the transitions as presently stated confound different levels of analysis because the model does not specifically deal with the fact that the input-output variables between different components are often conceptual or have fundamentally different units. Thus, the PCAD model in its present form provides little explicit direction towards a practical solution; we offer a step toward a solution by formalizing the functional connections between spatio-spectral-temporal variability in a free-ranging animal's ambient noise environment and the resultant loss of its opportunities to communicate. The task now is to better understand and constrain the uncertainties in the algorithm's variables, and to inform some of the simplifying assumptions (and test predicted ranges) with more empirical data. That will, of course, require addressing communication ranges within the proper ecological contexts and, more generally, the spaces over which different acoustic behaviors occur and change as a function of noise and other events.

We have adapted the term communication masking to the marine world of today, in which animals are confronted with a dynamic multitude of broadband sources added to a less dynamic, but steadily rising baseline of ambient noise that is considerably different (from the perspective of the animals) and more difficult to communicate in than the ambient acoustic ecology in which they evolved. The acoustic ecology of this modern habitat has changed significantly within the lifetime of an individual, thereby short-circuiting the normal operations of selection and adaptation. If animals are not pre-adapted or well adapted to compensate for changes in their ambient noise environment, they are left with few, if any, options by which to successfully communicate in anthropogenically modified acoustic habitats. There is some evidence that whales can, but sometimes do not, compensate for such changes in their ambient noise environment. For example, killer whales increase the amplitudes of their calls with increasing noise in the $1-40 \mathrm{kHz}$ frequency band (Holt et al. 2009), and blue whales increase their rate of social calling in the presence of noise from a seismic exploration sparker (Di Iorio \& Clark 2009). North Atlantic right whales have shifted the fundamental frequency of their contact calls by about an octave over a period of several decades, possibly as a result of long-term increases in ambient noise, but they reduce calling rate in response to increases in local ambient noise conditions (Parks et al. 2007).

Payne \& Webb (1971) were the first to raise the concern that noise from modern commercial shipping might reduce long-range communication for blue and fin whale singers. That hypothesis was ignored for a quarter of a century, during which ambient ocean noise levels continued to rise. By the century's turn that concern could no longer be ignored (e.g. NRC 2000, 2003). Numerous workshops were held to formally discuss and debate the problem (e.g. Southall 2005, Southall \& Scholik-Schlomer 2009), and in some cases those discussions have led to agreements on actions that could lead to reductions in ocean noise levels (Wright 2008).

As demonstrated here, the acoustic communication space for at least one species of large baleen whale, the highly endangered North Atlantic right whale, is seri- 
ously compromised by noise from commercial shipping traffic. It remains to be determined over what spatialspectral-temporal scales this conclusion is applicable to other species and other habitats.

As the planet's present dominant species, humans have choices to make. In the case of the ocean's acoustic ecological habitat, the choices we are making now have profound implications for the future of marine mammals. It is our opinion that the right choice cannot wait another 3 decades.

Acknowledgements. C.W.C. thanks Roger Payne for his numerous shared insights and our conversations on the topic of large-scale implications of anthropogenic noise on large whale, low-frequency acoustic communication; and George C. Gagnon (Ret. LCR US Navy) for sharing his insights and first-hand knowledge of low-frequency ocean acoustics, and for his unwavering quest for learning more about sound in the ocean. The authors are grateful for publications by or conversations with numerous colleagues, including Moira Brown, Peter Corkeron, Kurt Fristrup, David Kastak, Scott Kraus, Stormy Mayo, Susan Parks, Colleen Reichmuth, W. John Richardson, Rosalind Rolland, and Ronald Schusterman. We acknowledge scientists and staff at Stellwagen Bank National Marine Sanctuary and the Northeast Fisheries Science Center, and in particular Michael Thompson and Denise Risch. C.W.C. acknowledges the scientists, engineers and staff in the Bioacoustics Research Program at Cornell; particularly Tom Calupca, Robert MacCurdy, and Ildar Urazghildiiev for their assistance with data collection and analysis. David Janiger of the Natural History Museum of Los Angeles County assisted with the literature search. We thank W. John Richardson and 2 anonymous reviewers for constructive criticism of an earlier version of the manuscript. Funding for the data presented herein was provided under NOPP-ONR Grant \#N00014-07-1-1029 and contracts with Commonwealth of Massachusetts Division of Marine Fisheries, Excelerate Energy and Suez Energy LLC (C.W.C.).

\section{LITERATURE CITED}

Andrew RK, Howe BM, Mercer JA, Dzieciuch MA (2002) Ocean ambient sound: Comparing the 1960's with the 1990s for a receiver off the California coast. ARLO 3:65-70

Arons B (1992) A review of the cocktail party effect. J Am Voice I/O Soc 12:35-50

Au WWL (1993) The sonar of dolphins. Springer-Verlag, New York

Beranek LL, Ver IL (1992) Noise and vibration control engineering. Wiley, New York

Bregman AS (1990) Auditory scene analysis: the perceptual organization of sound. MIT Press, Cambridge, MA

Brenowitz EA (1982) The active space of red-winged blackbird song. J Comp Physiol [A] 147:511-522

Broadbent DE (1958) Perception and communication. Pergamon, New York

Brown CH (1989) The active space of blue monkey and greycheeked mangabey vocalizations. Anim Behav 37: 1023-1034

Brungart DS (2004) Informational and energetic masking effects in multitalker speech perception. In: Divenji P (ed) Speech separation by humans and machines. Kluwer Academic Press, Boston, MA, p 261-267
Cherry EC, Taylor WK (1954) Some further experiments upon the recognition of speech, with one and with two ears. J Acoust Soc Am 26:554-559

Clark CW (1983) Acoustic communication and behavior of the southern right whale (Eubalaena australis). In: Payne $\mathrm{R}$ (ed) Communication and behavior of whales. Westview Press, Boulder, CO, p 163-198

Clark CW (1989) Call tracks of bowhead whales based on call characteristics as an independent means of determining tracking parameters. Rep Int Whaling Comm 39:111-112

Clark CW (1990) Acoustic behavior of mysticete whales. In: Thomas J, Kastelein R (eds) Sensory abilities of cetaceans. Plenum Press, New York, p 580-583

Clark CW, Ellison WT (2004) Potential use of low-frequency sounds by baleen whales for probing the environment: evidence from models and empirical measurements. In: Thomas JA, Moss CF, Vater M (eds) Advances in the study of echolocation in bats and dolphins. University of Chicago Press, Chicago, IL, p 564-589

Clark CW, Gagnon GC (2002) Insights from IUSS detections, locations and tracking from 1992 to 1996. J Underwater Acoust 52:609-640

> Clark CW, Borsani JF, Notarbartolo di Sciara G (2002) Vocal activity of fin whales, Balaenoptera physalus, in the Ligurian Sea. Mar Mamm Sci 18:286-295

Clark CW, Gillespie D, Nowacek DP, Parks SE (2007) Listening to their world: Acoustics for monitoring and protecting right whales in an urbanized ocean. In: Kraus S, Rolland R (eds) The urban whale. Harvard University Press, Cambridge, MA, p 333-357

Cox TM, Ragen TJ, Read AJ, Vos E and others (2006) Understanding the impacts of anthropogenic sound on beaked whales. J Cetacean Res Manag 7:177-187

Croll DA, Clark CW, Acevedo A, Tershy B, Floress S, Gedamke J, Urban J (2002) Only male fin whales sing loud songs. Nature 417:809

Di Iorio L, Clark CW (2009) Exposure to seismic survey alters blue whale acoustic communication. Biol Lett doi: 10.1098/rsbl.2009.0651

Durlach NI, Colburn HS (1978) Binaural phenomena. In: Carterette EC, Friedman MP (eds) Handbook of perception, Vol IV. Academic Press, New York, p 365-455

> Ellison WT, Weixel K, Clark CW (1999) An acoustic integration model (AIM) for assessing the impact of underwater noise on marine wildlife. J Acoust Soc Am 106:2250

Erbe C, Farmer DM (2000) A software model to estimate zones of impact on marine mammals around anthropogenic noise. J Acoust Soc Am 108:1327-1331

Evans GW (2001) Environmental stress and health. In: Baum A, Revenson T, Singer JE (eds) Handbook of health psychology. Erlbaum Press, Mahway, NJ

> Evans GW (2003) A multimethodological analysis of cumulative risk and allostatic load among rural children. Dev Psychol 39:924-933

Fay RR (1988) Hearing in vertebrates: a psychophysics databook. Worcester Heffernan Press, Worcester, MA

Fay RR (1992) Structure and function of sound discrimination among vertebrates. In: Webster DB, Fay RR, Popper AN (eds) The evolutionary biology of hearing. SpringerVerlag, New York, p 229-263

> Finneran JJ, Oliver CW, Schaefer KM, Ridgway SH (2000) Source levels and estimated yellowfin tuna (Thunnus albacares) detection ranges for dolphin jaw pops, breaches, and tail slaps. J Acoust Soc Am 107:649-656

Fletcher H (1940) Auditory patterns. Rev Mod Phys 12:47-65

Frankel AS, Ellison WT, Buchanan J (2002) Application of the Acoustic Integration Model (AIM) to predict and minimize 
environmental impacts. IEEE Oceans 2002:1438-1443

Handel S (1989) Listening: an introduction to the perception of auditory events. MIT Press, Cambridge, MA

Harrison C, Harrison J (1995) A simple relationship between frequency and range averages for broadband sonar. J Acoust Soc Am 97:1314-1317

Hatch L, Clark C, Merrick R, Van Parijs S and others (2008) Characterizing the relative contributions of large vessels to total ocean noise fields: A case study using the Gerry E. Studds Stellwagen Bank National Marine Sanctuary. Environ Manage 42:735-752

Holt MM, Schusterman RJ (2007) Spatial release from masking of aerial tones in pinnipeds. J Acoust Soc Am 121: 1219-1225

Holt MM, Noren DP, Veirs V, Emmons CK, Veirs S (2009) Killer whales (Orcinus orca) increase their call amplitude in response to vessel noise. J Acoust Soc Am 125: EL27-EL32

Ihlefeld A, Shinn-Cunningham B (2008) Spatial release from energetic and informational masking in a selective speech identification task. J Acoust Soc Am 123:4369-4379

Janik VM (2000) Source levels and the estimated active space of bottlenose dolphin (Tursiops truncatus) whistles in the Moray Firth, Scotland. J Comp Physiol [A] 186:673-680

Kastelein RA, de Hann D, Verboom WC (2007) The influence of signal parameters on the sound source localization ability of a harbor porpoise (Phocoena phocoena). J Acoust Soc Am 122:1238-1248

Kryter KD (1994) The handbook of hearing and the effects of noise: physiology and public health. McGraw-Hill, New York

> McDonald MA, Hildebrand JA, Wiggins SM (2006) Increases in deep ocean ambient noise in the Northeast Pacific west of San Nicolas Island, California. J Acoust Soc Am 120: $711-718$

Miller JL (1997) Speech perception. In: Crocker MJ (ed) Encyclopedia of acoustics, Vol IV. John Wiley \& Sons, New York, p 1579-1588

Moore BCJ (1982) An introduction to the psychology of hearing. Academic Press, London

Moore SE, Stafford Kathleen M, Mellinger DK, Hildebrand JA (2006) Listening for large whales in the offshore waters of Alaska. BioScience 56:49-55

NRC (National Research Council) (2000) Marine mammals and low-frequency sound: progress since 1994. National Academies Press, Washington, DC

NRC (National Research Council) (2003) Ocean noise and marine mammals. National Academies Press, Washington, DC

NRC (National Research Council) (2005) Marine mammal populations and ocean noise: Determining when noise causes biologically significant effects. National Academies Press, Washington, DC

$>$ Niemiec AJ, Yost WA, Shofner WP (1992) Behavioral measures of frequency selectivity in the chinchilla. J Acoust Soc Am 92:2636-2649

Nilsson M, Sigfrid DS, Sullivan JA (1994) Development of the hearing in noise test for the measurement of speech reception thresholds in quiet and in noise. J Acoust Soc Am 95:1085-1099

Nowacek DP, Thorne LH, Johnston DW, Tyack PL (2007) Responses of cetaceans to anthropogenic noise. Mammal Rev 37:81-115

Parks SE, Clark CW, Tyack PL (2007) Short- and long-term changes in right whale calling behavior: The potential effects of noise on acoustic communication. J Acoust Soc Am 122:3725-3731
Payne RS, McVay S (1971) Songs of humpback whales. Science 173:585-597

Payne R, Webb D (1971) Orientation by means of long range acoustic signaling in baleen whales. Ann NY Acad Sci 188:110-142

Pearsons KS, Bennett RL, Fidell S (1977) Speech levels in various noise environments. US Environmental Protection Agency, Washington, DC

Peters S, Stubley P, Valin J (1999) On the limits of speech recognition in noise. In: Spanias A, Cochran D (eds) IEEE International Conference on Acoustics, Speech and Signal Processing. IEEE Computer Society, Washington, DC, p 365-368

Porter M, Reiss EL (1985) A numerical method for bottom interacting ocean acoustic normal modes. J Acoust Soc Am 77:1760-1767

> Premus V, Spiesberger JL (1997) Can acoustic multipath explain finback (B. physalus) $20-\mathrm{Hz}$ doublets in shallow water? J Acoust Soc Am 101:1127-1138

Reynolds JE III, Rommel SA (1999) Biology of marine mammals. Smithsonian Books, Washington, DC

Richardson WJ, Greene CR, Malme CI, Thomson DH (1995) Marine mammals and noise. Academic Press, San Diego, CA

Scharf B (1970) Critical bands. In: Tobias JV (ed) Foundations of modern auditory theory, Vol. 1. Academic Press, New York, p 159-202

Schultz TJ (1978) Synthesis of social surveys on noise annoyance. J Acoust Soc Am 64:377-405

Schusterman RJ (1981) Behavioral capabilities of seals and sea lions: a review of their hearing, visual, learning and diving skills. Psychol Rec 31:125-143

Southall BL (2005) 'Shipping noise and marine mammals: a forum for science, technology, and management.' Final report, National Oceanic and Atmospheric Administration, Washington, DC

Southall BL, Scholik-Schlomer A (2009) Potential application of vessel-quieting technology on large commercial vessels. Final Report of the National Oceanic and Atmospheric Administration (NOAA) International Conference. NOAA Fisheries, Silver Spring, MD

Southall BL, Schusterman RJ, Kastak D (2003) Acoustic communication ranges for northern elephant seals (Mirounga angustirostris). Aquat Mamm 29:202-213

Southall BL, Bowles AE, Ellison WT, Finneran JJ and others (2007) Marine mammal noise exposure criteria: Initial scientific recommendations. Aquat Mamm 33:411-414

Stafford KM, Mellinger DK, Moore SE, Fox CG (2007) Seasonal variability and detection range modeling of baleen whale calls in the Gulf of Alaska, 1999-2002. J Acoust Soc Am 122:3378-3390

Tafalla R, Evans G (1997) Noise, physiology, and human performance: the potential role of effort. J Occup Health Psychol 2:148-155

> Tanner WP (1958) What is masking? J Acoust Soc Am 30: 919-921

> Turnbull SD (1994) Changes in masked thresholds of a harbor seal (Phoca vitulina) associated with angular separation of signal and noise sources. Can J Zool 72:1863-1866

Tyack PL (1998) Acoustic communication under the sea. In: Hopp SL, Owren MJ, Evans CS (eds) Animal acoustic communication: Sound analysis and research methods. Springer-Verlag, New York, p 163-220

> Tyack PL (2008) Implications for marine mammals of largescale changes in the marine acoustic environment. J Mammal 89:549-558

Urick RJ (1983) Principles of underwater sound. McGrawHill, New York 
Wartzok D, Ketten DR (1999) Marine mammal sensory systems. In: Reynolds JE III, Rommel SA (eds) Biology of marine mammals. Smithsonian Institute Press, Washington, DC, p 117-175

Watkins WA (1981) Activities and underwater sounds of fin whales. Sci Rep Whales Res Inst 33:83-117

Watkins WA, Schevill WE (1979) Aerial observation of feeding behavior in four baleen whales: Eubalaena glacialis, Balaenoptera borealis, Megaptera novaeangliae, and Balaenoptera physalus. J Mammal 60:155-163

Watkins WA, Tyack P, Moore KE (1987) The 20-Hz signals of finback whales (Balaenoptera physalus). J Acoust Soc Am 82:1901-1912

Watkins WA, Daher MA, George JE, Rodriguez D (2004) Twelve years of tracking 52-Hz whale calls from a unique source in the North Pacific. Deep Sea Res I 51:1889-1901

Submitted: December 26, 2008; Accepted: November 9, 2009
Watson CS (1987) Uncertainty, informational masking and the capacity of immediate auditory memory. In: Yost WA, Watson CS (eds) Auditory processing of complex sounds. Erlbaum, Hillsdale, NJ, p 267-277

Wegel RL, Lane CE (1924) The auditory masking of one pure tone by another and its probable relation to the dynamics of the inner ear. Phys Rev 23:266-285

Wright AJ (ed) (2008) International Workshop on Shipping Noise and Marine Mammals, Hamburg, Germany, 21-24 April 2008. Okeanos - Foundation for the Sea, Darmstadt. Available from www.sound-in-the-sea.org/download/ ship2008_en.pdf

Yost WA (2000) Fundamentals of hearing. Academic Press, San Diego, CA

Yost WA, Popper AN, Fay RR (2008) Auditory perception of sound sources. Springer, New York

Proofs received from author(s): November 29, 2009 